\title{
Interactions between perceptions of fatigue, effort, and affect decrease knee extensor endurance performance following upper body motor activity, independent of changes in neuromuscular function
}

\author{
A. Greenhouse-Tucknott ${ }^{1}$ \\ J. G. Wrightson ${ }^{1,2}$ (D) \\ M. Raynsford ${ }^{1}$ \\ N. A. Harrison $3,4,5$ \\ J. Dekerle ${ }^{1}$ (iD)
}

${ }^{1}$ Fatigue and Exercise Laboratory, University of Brighton, Brighton, UK

${ }^{2}$ Department of Clinical Neurosciences, Cumming School of Medicine, University of Calgary, Calgary, Alberta, Canada

${ }^{3}$ Immunopsychiatry Research Group, Cardiff University, Cardiff, UK

${ }^{4}$ Department of Neuroscience, Brighton and Sussex Medical School, University of Sussex, Brighton, UK

${ }^{5}$ Sussex Partnership NHS Foundation Trust, Brighton, UK

\section{Correspondence}

A. Greenhouse-Tucknott, Fatigue and Exercise Laboratory, University of Brighton, Brighton, East Sussex, UK. Email: A.Greenhouse-Tucknott@brighton. ac.uk

\begin{abstract}
Prior exercise has previously been shown to impair subsequent endurance performance in non-activated muscles. Declines in the neuromuscular function and altered perceptual/affective responses offer possible mechanisms through which endurance performance may be limited in these remote muscle groups. We thus conducted two experiments to better understand these performance-limiting mechanisms. In the first experiment, we examined the effect of prior handgrip exercise on the behavioral, perceptual, and affective responses to a sustained, sub-maximal contraction of the knee extensors. In the second experiment, transcranial magnetic stimulation was used to assess the neuromuscular function of the knee extensors before and after the handgrip exercise. The results of the first experiment demonstrated prior handgrip exercise increased the perceptions of effort and reduced affective valence during the subsequent knee extensor endurance exercise. Both effort and affect were associated with endurance performance. Subjective ratings of fatigue were also increased by the preceding handgrip exercise but were not directly related to knee extensor endurance performance. However, perceptions of fatigue were correlated with heightened effort perception and reduced affect during the knee extensor contraction. In the second experiment, prior handgrip exercise did not significantly alter the neuromuscular function of the knee extensors. The findings of the present study indicate that motor performance in the lower limbs following demanding exercise in the upper body appears to be regulated by complex, cognitive-emotional interactions, which may emerge independent of altered neuromuscular function. Subjective fatigue states are implicated in the control of perceptual and affective processes responsible for the regulation of endurance performance.
\end{abstract}

\section{K E Y W O R D S}

affect, exercise tolerance, fatigue, perception of effort, TMS, voluntary activation

This is an open access article under the terms of the Creative Commons Attribution License, which permits use, distribution and reproduction in any medium, provided the original work is properly cited.

๑ 2020 The Authors. Psychophysiology published by Wiley Periodicals LLC on behalf of Society for Psychophysiological Research 


\section{1 | INTRODUCTION}

For more than a century it has been recognized that sustained cognitive and physical work impairs physical performance and/or increases the subjective feelings of fatigue (Mosso, 1891). Though related (e.g., Loy, Taylor, Fling, \& Horak, 2017), disassociation of these physiological and perceptual factors may provide critical insight into the nature and principal mechanisms of fatigue. For example, under certain neurological conditions, heightened perceptions of fatigue may be recorded independent of discernible motor dysfunction (de Lima et al., 2018; Dunaway Young et al., 2019; Prak, van der Naalt, \& Zijdewind, 2019). In exercise, perceptual changes may similarly hold particular interest, since endurance performance has been shown, ultimately, to be limited by the attainment of maximal perceived effort rather than an inability of the muscles to meet the power or force requirements of the task (Marcora \& Staiano, 2010; Staiano, Bosio, de Morree, Rampinini, \& Marcora, 2018). Further investigation of the interactions between perceptual factors and motor changes during exercise may therefore aid the understanding of the fundamental basis of fatigue.

Emerging experimental paradigms including, for example, prior cognitive and remote physical tasks, have proved successful in manipulating perceptual responses during subsequent physical endurance exercise without directly challenging the neuromuscular system's capacity to produce force (Amann et al., 2013; Pageaux, Marcora, \& Lepers, 2013). These paradigms may thus offer a means of investigating the perceptual regulation of exercise in isolation. For example, prior motor activity has been shown to reduce endurance performance in remote non-activated muscles (Amann et al., 2013; Bangsbo, Madsen, Kiens, \& Richter, 1996; Johnson, Sharpe, Williams, \& Hannah, 2015; Morgan et al., 2019; Nordsborg et al., 2003), increasing the perception of exertion or effort during the endurance task independent of observable changes in the neuromuscular function (Amann et al., 2013; Johnson et al., 2015; Morgan et al., 2019).

The perception of effort (i.e., the conscious sensation of how hard, heavy or strenuous exercise is, Marcora, 2010) is proposed as the cardinal limiter of endurance performance (Staiano et al., 2018). Effort perception is widely accepted to originate centrally, emerging from the corollary discharge of volitional motor commands from premotor or motor regions to sensory areas of the brain (de Morree, Klein, \& Marcora, 2012; Zénon, Sidibé, \& Olivier, 2015). Activation of small-diameter afferent fibers have also been posited to contribute to effort perception (Broxterman et al., 2017, 2018), though this remains controversial and is highly disputed by some (Barbosa et al., 2016; Mitchell, Reeves, Rogers, \& Secher, 1989; Smith et al., 2003; see Marcora, 2009; Pageaux \& Gaveau, 2016). Homeostatic afferent feedback is, however, considered the basis of our emotional (affective) experiences
(Craig, 2002; Damasio \& Carvalho, 2013) and as such, affective responses have also been associated with the physical endurance performance (Hartman, Ekkekakis, Dicks, \& Pettitt, 2019; Jones et al., 2015). While effort rather than affect has dominated the study of the limits of endurance performance to date, an ability to disassociate effort and affect, that is, the what from how one feels (Hardy \& Rejeski, 1989), may indicate disparate neurophysiological and behavioral functions. The interplay between the perception of effort and affect requires further investigation.

Furthermore, though the perception of effort is a central tenant of many behavioral models of fatigue (Hockey, 2011; Kuppuswamy, 2017; Marcora, 2008; Noakes, 2012), perceptions of fatigue and effort are distinct constructs (Borg, 1986; Halperin \& Emanuel, 2020). Micklewright, St Clair Gibson, Gladwell, and Al Salman (2017) recently demonstrated that the perception of fatigue and effort could be disassociated during recovery following exhaustive exercise. In this study, the perception of fatigue was defined as a "feeling of diminishing capacity to cope with physical or mental stressors, either imagined or real" (Micklewright et al., 2017). While the association between perceived effort and volitional exercise behaviors is relatively well established (e.g., Christian, Bishop, Billaut, \& Girard, 2014), understanding of the behavioral correlates of fatigue perceptions are less so. Recently, heightened perceptions of (mental) fatigue, evoked through demanding cognitive activity, were unrelated to subsequent self-selected cycling intensities but were correlated with the level of effort perceived during the cycling bout (Harris \& Bray, 2019). This may suggest that the subjective experience of fatigue does not directly influence behavior, however, may function indirectly, ultimately limiting exercise by making it feel more effortful. Interactive relationships between perceptions of fatigue and effort have previously been postulated, but the nature of such a relationship (and similarly between fatigue and core affective responses) is not entirely clear (Kuppuswamy, 2017).

Finally, though previous assertions indicate a separation between perceptual responses to exercise and neuromuscular function following prior, remote exercise, the effect of prior exercise on the neuromuscular function in non-active, remote muscles remains ambiguous (see Halperin, Chapman, $\&$ Behm, 2015). Evidence of impaired maximal force production in non-active muscle groups following remote exercise is currently equivocal (Doix et al., 2018; Doix, Lefèvre, \& Colson, 2013; Rattey, Martin, Kay, Cannon, \& Marino, 2006; Šambaher, Aboodarda, \& Behm, 2016; Sidhu et al., 2014; Triscott et al., 2008). Moreover, transcranial magnetic stimulation (TMS) studies have reported both excitatory and inhibitory effects on the excitability of the corticospinal tract of remote muscle groups (Aboodarda, Šambaher, Millet, \& Behm, 2017; Šambaher et al., 2016). As reductions in the neuromuscular function may modulate the perceptual consequences of action, for example, increase the perception of 
effort (Lampropoulou \& Nowicky, 2014; Marcora, Bosio, \& de Morree, 2008), and therefore underpin endurance performance impairments, further investigation of the disassociation of neuromuscular and perceptual responses in non-active muscle groups is required to fully contextualize any study of endurance performance regulation.

Here, we used prior remote exercise in the upper limbs (handgrip; HG) to examine the behavioral, perceptual/affective, and neuromuscular responses to a sustained submaximal contraction of the knee extensors (KE). We first hypothesized that prior HG exercise would increase the perception of fatigue, perception of effort, and negative affect, resulting in impaired endurance performance during subsequent KE exercise. Relationships between perceptual/affective constructs were subsequently explored. In a second experiment, we quantified changes in the neuromuscular function of the $\mathrm{KE}$ following prior $\mathrm{HG}$ exercise. It was hypothesized that force production and cortical voluntary activation of the KE would be unchanged by the prior HG task.

\section{$2 \mid$ METHOD}

\section{1 | Participants}

The study was approved by the University of Brighton Research Ethics Committee (SSCREC18-09) with experimental procedures conducted in accordance with the Declaration of Helsinki, except for prior registration in a database. Twenty healthy male participants (mean $\pm S D$; age: $25 \pm 4$ years; weight: $81.2 \pm 9.0 \mathrm{~kg}$; height: $1.82 \pm 0.07 \mathrm{~m})$ were recruited for the first experiment. All were medication-free and had no history of cardiovascular, neurological or musculoskeletal disorders. Hand (16 Right) and leg (15 Right) dominance was determined using the Edinburgh Handedness Inventory (EHI) (Oldfield, 1971). A sub-sample $(N=15 ; 25 \pm 4$ years; weight: $81.1 \pm 9.9 \mathrm{~kg}$; height: $1.82 \pm 0.07 \mathrm{~m} ; 13$ right-handed, 12 right-legged) volunteered to take part in the second experiment. All screened negative for contraindications to TMS (Rossi, Hallett, Rossini, \& Pascual-Leone, 2011). All participants were instructed to refrain from caffeine, alcohol, and strenuous exercise for $24 \mathrm{hr}$ prior to each testing session.

\subsection{Experiment one}

Participants attended three separate sessions, conducted at the same time of day $( \pm 2 \mathrm{hr}$ ) with sessions separated by a minimum of $48 \mathrm{hr}$. In the preliminary session, participants were familiarised with all measures and maximal $\mathrm{HG}$ and $\mathrm{KE}$ force was determined. In the subsequent two experimental sessions, participants undertook a bilateral, intermittent HG exercise task and time-matched control task (passive rest). $\mathrm{KE}$ endurance performance was evaluated after $(10 \mathrm{~s})$ each task (Figure 1a). The KE endurance exercise task was a sustained isometric contraction of the dominant $\mathrm{KE}$ at $20 \%$ maximal voluntary contraction (MVC) performed until task failure. Task failure was defined as an inability to maintain the target force for $>3 \mathrm{~s}$. The session order was randomized and counterbalanced across participants.

The HG exercise, based on the fatiguing protocol described by Gruet et al. (2014), consisted of repeated bilateral, sustained isometric contractions at 30\% MVC for $15 \mathrm{~s}$, followed immediately by a $5 \mathrm{~s}$ MVC. Each contraction was separated by $10 \mathrm{~s}$ rest. During the preliminary session, the sequence was performed until task failure (voluntary force below $30 \%$ MVC for $>2 \mathrm{~s}$ ) in the dominant hand. To standardize task duration across conditions, participants performed only the number of successfully completed contraction sequences achieved during the preliminary session (mean duration: $308.0 \pm 95.6$ s; range: $140-470$ s; $11 \pm 3$ repetitions). Strong verbal encouragement was provided throughout the HG, but not the KE task to prevent potential experimenter bias from influencing performance on the endurance task. Participants were instructed to relax their legs during the HG task (average VL EMG $<0.03 \mathrm{mV}$ ). Target submaximal forces were determined for both tasks based on the highest values recorded during the preliminary session (maximal force production did not differ from the preliminary session during experimental trials; $p>.05$, data not shown). Visual feedback of force production was presented on a monitor, with participants naïve to both elapsed time and task failure criteria.

Electromyographic (EMG) activity of the quadriceps (vastus lateralis: $\mathrm{VL}$ ) was recorded throughout the KE endurance task, while perceived effort and affective state were assessed every $30 \mathrm{~s}$ in pseudorandomized order. Perception of effort, defined as "the conscious sensation of how hard, heavy and strenuous exercise is" (Marcora, 2010), was measured using the Borg CR-10 scale (Borg, 1982). Participants were instructed to disassociate feelings of pain and discomfort from the perception of effort, with effort representing how strenuous the exercise felt at a given point in time. Experiential anchors were set with 0 representing no effort and 10 the degree of effort felt during the strongest contraction they had previously experienced (max effort). Changes in participants' affect during the KE contraction were assessed using the Feeling Scale (FS; range +5 to -5 ), through which participants were asked to rate their current mood state during the KE contraction, with positive integers representing pleasurable affective states and negative integers unpleasurable affective states (Hardy \& Rejeski, 1989). The extremes of the scale were anchored based on experiential factors related to prior exercise experiences, with +5 representing individuals' most pleasant experience during previous physical activity and -5 their most unpleasant experience. Subjective ratings 

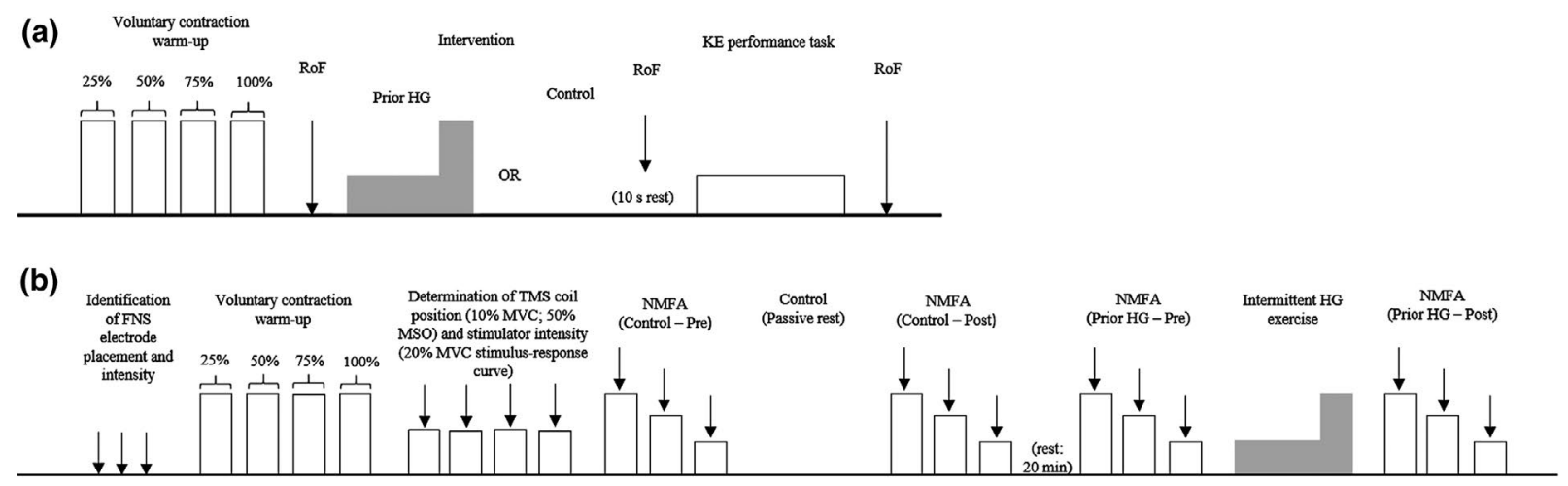

(c)

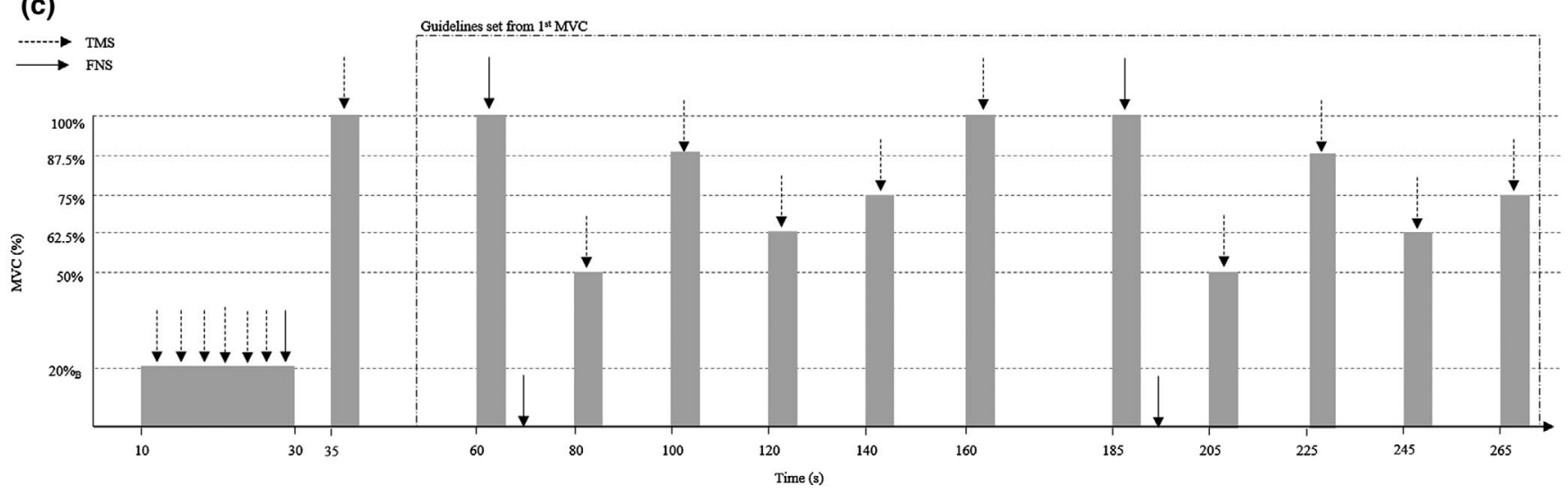

F I G URE 1 Schematic overview of experimental design. (a) Experiment one, (b) experiment two, and (c) overview of the neuromuscular assessment protocol for experiment two. FNS, Femoral nerve stimulation; KE, Knee extensor; MSO, Maximal stimulator output; MVC, Maximal voluntary contraction; NMFA, Neuromuscular fatigue assessment; Prior HG, Intermittent handgrip task; RoF, Rating of fatigue; TMS, Transcranial magnetic stimulation

of fatigue (RoF) were captured before the HG task and immediately after both the HG task and the KE task using an 11-point scale (Micklewright et al., 2017). The perception of fatigue was defined as a "feeling of diminishing capacity to cope with physical or mental stressors, either imagined or real" (Micklewright et al., 2017). Instructions and anchoring procedures presented to participants conformed to the authors' description, except for examples referencing the propensity to sleep or the feelings experienced upon waking. These examples were excluded based on recommendations to clearly distinguish feelings of fatigue from those of sleepiness (Pigeon, Sateia, \& Ferguson, 2003).

\section{3 $\mid$ Experiment two}

The single session was conducted at the same time of day as individual sessions performed in experiment one. Neuromuscular assessments were performed before and after the control and HG tasks (described above), which were presented in a constant order (Figure 1b). The neuromuscular assessment began with a $30 \mathrm{~s} \mathrm{KE}$ contraction performed at $20 \%$ of baseline MVC $\left(20 \%_{\mathrm{B}}\right)$. Six TMS pulses were delivered during the sustained contraction (one every $4 \mathrm{~s}$ ), with femoral nerve stimulation (FNS) applied prior to the end of the contraction. Following a brief rest $(5 \mathrm{~s})$, two series of six contractions were then performed each comprising: (a) an MVC with superimposed TMS; (b) an MVC with FNS superimposed and applied immediately after the contraction ( $2 \mathrm{~s}$ delay); (c) four submaximal contractions performed sequentially at $50 \%$, $87.5 \%, 62.5 \%$, and $75 \%$ of MVC each with superimposed TMS (Dekerle, Greenhouse-Tucknott, Wrightson, Schäfer, \& Ansdell, 2019). MVCs were separated by $20 \mathrm{~s}$, with each submaximal contraction separated by $15 \mathrm{~s}$. The two contraction series were also separated by $15 \mathrm{~s}$ (Figure 1c). Target force levels were derived from the first MVC and displayed as visual guidelines, with participants asked to attempt to surpass the guideline during each subsequent MVC. All contractions were $5 \mathrm{~s}$ in duration. The post-HG exercise evaluation protocol was initiated $10 \mathrm{~s}$ after completing the fatiguing task.

All experimental sessions (across both experiments) started with a standardized warm-up, consisting of four bilateral handgrip contractions at $25 \%, 50 \%$, and $75 \%$ of perceived maximal force (Kennedy, Hug, Sveistrup, \& Guével, 2013). Participants then performed MVCs, alternating between hands (1 min separating each contraction) until the coefficient of variation across three successive trials for the same hand was $<5 \%$. The same procedure was replicated in the KE. 


\subsection{1 $\quad$ Femoral nerve stimulation}

Single percutaneous electrical stimuli (duration: $200 \mu \mathrm{s}$ ) were delivered to the right femoral nerve via a pair of square $(5 \times 5 \mathrm{~cm})$ self-adhesive neuro-stimulation electrodes (Valutrode CF5050; Axelgaard Manufacturing Co., Ltd., California, USA), attached to a high-voltage (maximal voltage: $400 \mathrm{~V}$ ) constant-current stimulator (Model DS7AH, Digitimer Ltd., Hertfordshire, UK). The cathode was placed high in the femoral triangle with the anode positioned midway between the ipsilateral greater trochanter and iliac crest (Sidhu, Bentley, \& Carroll, 2009). The precise location of cathode placement was determined through the systematic adjustments of the electrode until the greatest amplitude for twitch force $\left(Q_{\mathrm{tw}}\right)$ and $\mathrm{M}$-wave amplitude for a given sub-maximal current ( 70-90 mA) was attained (Johnson et al., 2015). Optimal stimulation intensity was defined as the intensity at which a plateau in both $Q_{\mathrm{tw}}$ and M-wave was exhibited. Optimal stimulation intensity was determined through progressive increments in stimulator current (+20 mA) from $10 \mathrm{~mA}$, with two stimuli delivered at each intensity. Stimulation intensity was increased by a further $30 \%$ in order to ensure full spatial recruitment of KE motor units $(140 \pm 40 \mathrm{~mA})$.

\subsection{2 | Transcranial magnetic stimulation}

Single, monophasic magnetic stimuli (duration: $1 \mathrm{~ms}$ ) were manually delivered over the contralateral primary motor cortex, powered by a magnetic stimulator (Magstim ${ }^{200}$, The Magstim Company Ltd., Whitland, UK), using a concave (110 mm) double-cone coil. The orientation of the coil was positioned to induce a posterior-anterior intracranial current flow within the cortex. The optimal coil position for the activation of the KE was determined through marking vertex, 1 , and $2 \mathrm{~cm}$ posterior to vertex and $1 \mathrm{~cm}$ contralateral to each mark along the midline (i.e., 6 marks) (Souron, Besson, Mcneil, Lapole, \& Millet, 2018). The site eliciting the largest motor evoked potential (MEP) amplitude in the quadriceps and superimposed twitch (SIT) force, whilst minimizing MEP amplitude in the antagonist BF, during a 10\% MVC KE contraction at 50\% maximal stimulator output (MSO) was chosen. If peak amplitude and SIT force were not evoked at the same site, MEP amplitude was prioritized due to the influence of co-activation on SIT responses (Todd, Taylor, \& Gandevia, 2016). Optimal stimulus intensity (65 $\pm 13 \%$ MSO) was determined through SIT and MEP stimulus-response curves during brief ( $3 \mathrm{~s}$ ) contractions of the $\mathrm{KE}$ at 20\% MVC (Temesi, Gruet, Rupp, Verges, \& Millet, 2014). Stimulator intensities of 20\%, 30\%, 40\%, 50\%, 60\%, 70\%, and $80 \%$ MSO were each applied during four contractions, performed at $10 \mathrm{~s}$ intervals. Stimulator intensities were presented in a randomized order with $10 \mathrm{~s}$ between each intensity set. If plateaus in SIT and MEP amplitudes were not evident, higher stimulator intensities were investigated (e.g., 90\% MSO). A plateau in the stimulator-response curve was defined as the lowest intensity resulting in an increase of $<5 \%$ of MEP amplitude with an increase in intensity (Temesi et al., 2014). The antagonist MEP amplitude was monitored in order to ensure co-activation was minimized.

\section{4 | Force and electromyography recordings}

Participants were seated, upright on a custom high-backed chair with hip and knee angles set at $90^{\circ}\left(0^{\circ}=\right.$ full extension $)$. The upper torso was secured to the back of the chair via two noncompliant cross-over shoulder straps, minimizing extraneous movement of the upper body. A cervical neck brace was used to constrain movements of the head. Contraction force of the KE was measured via a calibrated load cell (Model 615, Vishay Precision Group, Basingstoke, UK), secured to the lower leg via a cuff fastened slightly superior $(2-4 \mathrm{~cm})$ of the lateral malleoli, which attached to a custom-built bridge amplifier (Type 132-C, Datum Electronics, Isle of Wight, UK). Participants' forearms were strapped across the forearm and wrist, in a supinated position (elbow angle set at approximately $70^{\circ} ; 0^{\circ}=$ full extension), to a custom table positioned in front of the rig. In each hand, participants held a handgrip transducer (MLT003/D; ADInstruments, Colorado Springs, CO). Participants held each transducer with a standardized grip posture. Force was digitized $(4 \mathrm{kHz})$ and analyzed using LabChart v7.0 software (ADInstruments, Oxfordshire, UK). Surface EMG activity was recorded from the dominant VL and bicep femoris (BF) with pairs of self-adhesive electrodes (Kendall ${ }^{\mathrm{TM}}$ H59P, Coviden, Massachusettes, USA), positioned in accordance to SENIAM guidelines (Hermens, Freriks, Disselhorst-Klug, \& Rau, 2000). The reference electrode was placed on the ipsilateral patella. The skin-electrode interface was prepared by shaving the area, lightly abrading, and cleansing with isopropyl alcohol to minimize electrical resistance. EMG signals were amplified (gain $\times 1000)$ (PowerLab 26T; ADInstruments, Oxfordshire, UK), digital band-pass filtered $(20-2,000 \mathrm{~Hz})$, digitized $(4 \mathrm{kHz})$, recorded, and later analyzed offline (LabChart v7.0).

\section{5 | Data analysis}

\subsection{1 | Force}

Maximal and sub-maximal voluntary contraction force was defined as the greatest $500 \mathrm{~ms}$ average prior to stimulation. MVC force represented the highest voluntary force recorded at each assessment period. The percentage change in $\mathrm{HG}$ 
MVC force was quantified from the initial MVC (following the warm-up) to the last MVC of the task. In experiment two, the amplitude of evoked mechanical variables (i.e., SIT, $Q_{\mathrm{tw}}$ ) was analyzed for each stimulation at a given force level and then averaged across the two contraction sequences.

\subsection{2 | Voluntary activation $\left(\mathrm{VA}_{\mathrm{TMS}}\right)$}

Following the principles of twitch interpolation, $\mathrm{VA}_{\mathrm{TMS}}$ was quantified using the equation: $\mathrm{VA}_{\mathrm{TMS}}=1-(\mathrm{SIT} / \mathrm{ERT}) \times$ 100. Estimated resting twitch (ERT) was derived through the linear regression of TMS-evoked SIT amplitude and voluntary torque. Ten points were added to each linear model (Dekerle et al., 2019). All regression analyses were statistically significant $(p<.01)$ and showed a strong linear relationship: $\left(r^{2}\right) .89 \pm .04, .89 \pm .07, .90 \pm .06$ and $.89 \pm .08$ pre and post control and pre and post the HG task, respectively. stimulation. VL RMS and MPF were calculated over consecutive 15 s sampling intervals during the KE performance task and normalized to values recorded during MVCs. In experiment two, MEP and $M_{\max }$ were analyzed for peak-to-peak amplitudes. MEP and $M_{\max }$ responses from one representative participant are presented in Figure 2. VL MEPs were normalized to the nearest $\mathrm{M}$-wave evoked during a maximal contraction $\left(M_{\max }\right)$. MEPs recorded during $20 \%_{\mathrm{B}}$ were normalized to the $M_{\max }$ at the end of the same contraction $\left(M_{\max }\right.$ $20 \% \mathrm{~B}$ ). Absolute antagonist MEP amplitudes were recorded at each force level. For each level of contraction from $50 \%$ to $100 \% \mathrm{MVC}$, MEP responses were the average of the two responses evoked in the two contraction sequences. Across conditions, MEPs during $20 \%_{\mathrm{B}}$ demonstrated an effect of time, with the first two responses significantly lower than the successive stimulations $(p<.05)$. The first two MEPs were subsequently removed, with analysis performed on an average of the last four stimulations.

\subsection{3 | EMG}

Maximal root mean square $\left(\mathrm{RMS}_{\mathrm{Max}}\right)$ and mean power frequency $\left(\mathrm{MPF}_{\mathrm{Max}}\right)$ were obtained from a $500 \mathrm{~ms}$ interval centered on the highest recorded $\mathrm{KE}$ force value prior to

\subsection{4 $\quad$ Effort and affect}

The rate of change was calculated as the change in effort and affect from the first to the last response provided, as a function of time.
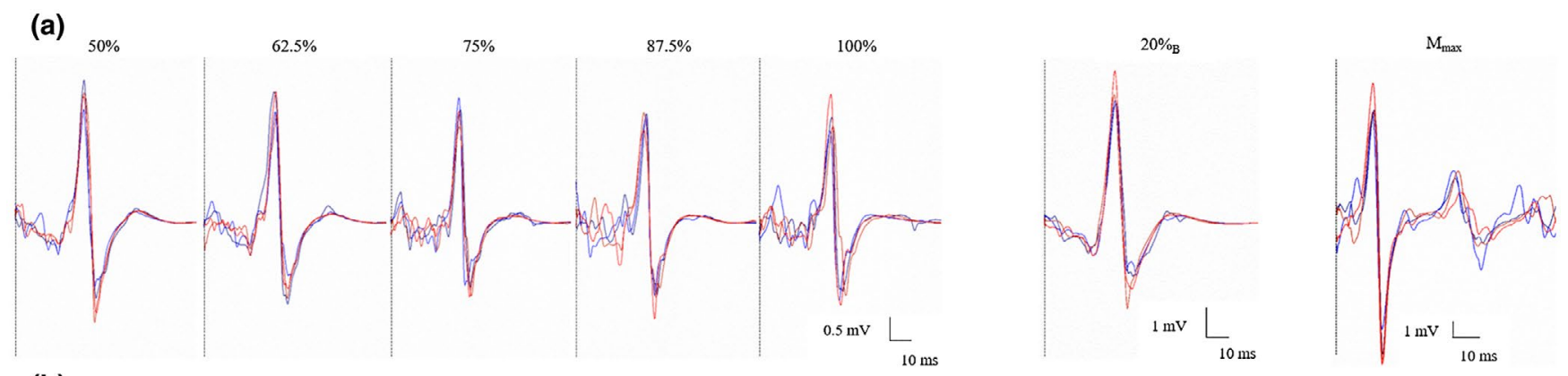

(b)

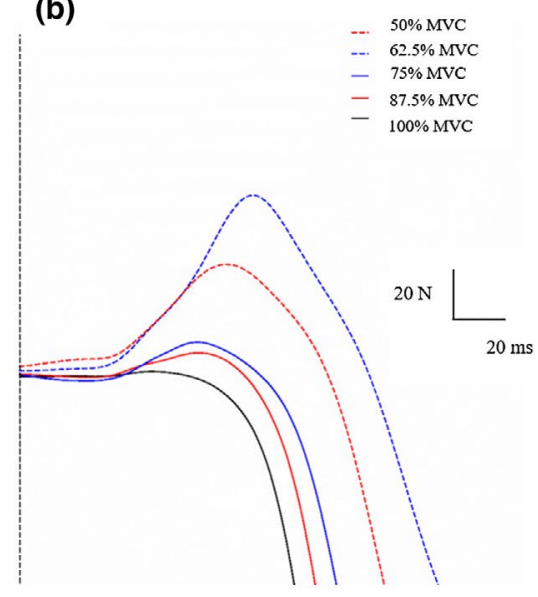

F I G URE 2 Representative traces of motor evoked potential (MEP) at each voluntary force level and $M_{\max }$ (a). Blue line: controlpreintervention. Dark blue line: control—postintervention. Red line: prior HG—preintervention. Dark red line: Prior HG—postintervention. Raw traces of example superimposed twitches evoked during maximal voluntary contraction (100\% MVC) and submaximal forces $(50 \%, 62.5 \%, 75 \%$, and $87.5 \%$ MVC) (b). Dotted black line represents the point of magnetic or electrical stimulation 


\section{6 | Statistical analysis}

Statistical procedures were performed using Statistical Package for the Social Sciences (SPSS Inc., v25, Chicago, IL) unless stated otherwise. Gaussian distributions were verified using a combination of normal $Q-Q$ plots and ShapiroWilk tests. Sphericity was assessed using Maulchy's test, with Greenhouse-Geisser correction applied as appropriate $(\varepsilon<0.75)$. In experiment one, time to task failure (TTF) violated the assumptions of normality and was thus analyzed using a Wilcoxon signed-rank test. Effort and affective responses were analyzed at each time point up to sample iso-time (i.e., time from the beginning of the $\mathrm{KE}$ endurance task to the penultimate measurement before task failure in the shortest performance). In this instance, responses at 30 and $60 \mathrm{~s}$ were compared across conditions using a two-way $(2 \times 2)$ repeated measures ANOVA. Effort and affective responses at task failure were not included in this general linear model due to observed ceiling and floor effects, respectively. Instead, effort and affect at task failure were assessed using Wilcoxon signed-rank tests, due to the violations of the assumptions of normality. RoF was assessed using a two-way, repeated measures $(2 \times 3)$ ANOVA. The effect of prior HG exercise on EMG RMS and MPF of the VL were analyzed with a two-way $(2 \times 7)$ repeated measures ANOVA up to sample iso-time, with values at task failure analyzed using paired-sample $t$ tests. The analysis was performed on $N=19$, as one participant was removed from the analysis due to the loss of EMG signal during the endurance task in one trial. Exploratory Spearman's rank correlation coefficients assessed the relationships between TTF and select perceptual and affective variables within each condition separately, with the false discovery (FDR) rate adjusted for multiple comparisons (Benjamini \& Yosef, 2000; Pike, 2011). Within-participant, repeated measures correlations were used to assess the relationships between perceptual and affective responses using the rmcorr package (Bakdash \& Marusich, 2017) in R (R Core Team, 2018). This was performed to assess relationships across a larger range of subjective fatigue responses.

In experiment two, mechanical and EMG responses were analyzed with a two-way $(2 \times 2)$ repeated-measures ANOVA. Significant main effects of time and interaction effects were followed up with Bonferroni adjusted pairwise comparisons. Data that violated the assumption of normality (i.e., $M_{\max }$, BF MEPS) were $\log (10)$ transformed. Tests of equivalence were also performed to test the null hypotheses of experiment two in jamovi (v1.0, The jamovi project, 2019) using the TOSTER package for $\mathrm{R}$ (Lakens, 2017). Tests of equivalence were performed between conditions on the pre-to-post change in the mechanical and EMG variables.

Data for parametric analyses were reported as mean $\pm S D$, while non-parametric analyses were reported as median
$(M d n)$ plus interquartile range $(I Q R)$, unless otherwise stated. Effect sizes for main effects are presented as partial eta squared $\left(\eta_{p}^{2}\right)$, while the pairwise comparison of mean differences are presented as Cohen's $d_{\mathrm{av}}$ (Lakens, 2013) for parametric data, and coefficients of correlation $(r=z / \sqrt{ } N)$ for non-parametric analyses. The null hypothesis was rejected at an $\alpha$-level of .05.

\section{3 | RESULTS}

\section{1 | Experiment one}

\subsubsection{Handgrip task and knee extension endurance performance: TTF}

The HG task induced substantial reductions in maximal force production in both the dominant $(-47.0 \pm 10.1 \%$; range: -28.0 to $-68.1 \%)$ and non-dominant hand $(-45.2 \pm 10.4 \%$; range: -23.3 to $-63.2 \%)$, with no difference between hands $\left(t_{(19)}=-1.17, p=.258, d_{\mathrm{av}}=0.18\right)$. Importantly, prior HG activity significantly impaired KE endurance performance (prior HG: Mdn: $230.5 \mathrm{~s}$ [191-332 s], control: Mdn: 257.0 s [197.25-363 s]; $Z=$ $-2.24, p=.025, r=.35)$. Reductions were evidenced in 15 of 20 participants and resulted in a mean reduction of $11.1 \pm 20.8 \%$ (Figure 3).

\subsection{2 | Perception of effort, affect, and RoF during knee extension endurance task}

Effort and affective responses are presented in Table 1. Heightened effort perception was observed in the prior $\mathrm{HG}$ condition $\left(F_{(1,19)}=4.46, p=.048, \eta_{p}^{2}=0.518\right)$ and across time $\left(F_{(1,19)}=30.92, p<.001, \eta_{p}^{2}=0.619\right)$, but no interaction between condition and time was observed $\left(F_{(1,19)}=3.26, p\right.$ $=.087, \eta_{p}^{2}=0.146$ ). Effort at task failure was maximal (or near maximal) in both the prior HG and control condition $(Z=0.56, p=.577, r=.09)$. Similarly, affect was reduced by prior $\mathrm{HG}$ activity compared to the control condition $\left(F_{(1,19)}=\right.$ $\left.9.80, p=.006, \eta_{p}^{2}=0.340\right)$, and declined across time $\left(F_{(1,19)}=\right.$ $\left.8.00, p=.011, \eta_{p}^{2}=0.296\right)$. There was no interaction between condition and time $\left(F_{(1,19)}=1.09, p=.309, \eta_{p}^{2}=0.054\right)$ and there was no difference in affect at task failure $(Z=-0.54, p$ $=.589, r=-.09$ ).

A main effect of condition $\left(F_{(1,19)}=50.63, p<.001\right.$, $\left.\eta_{p}^{2}=0.727\right)$, time $\left(F_{(1.22,23.11)}=61.05, p<.001, \eta_{p}^{2}=0.763\right)$, and interaction $\left(F_{(1.54,29.16)}=72.84, p<.001, \eta_{p}^{2}=0.793\right)$ was observed for RoF. Pairwise comparisons showed that RoF were elevated by the HG task $\left(t_{(19)}=-12.07, p<\right.$ $\left..001 ; d_{\mathrm{av}}=3.01\right)$ and was increased further by the completion of the KE task $\left(t_{(19)}=-2.79, p=.035 ; d_{\mathrm{av}}=0.49\right)$. In 
FIG URE 3 Effect of prior handgrip (HG) exercise on time to task failure in the knee extensor (KE) endurance task. Connected grey points represent paired performance times for a given participant. Colored bars represent $M d n$ and $I Q R$. $N=20$

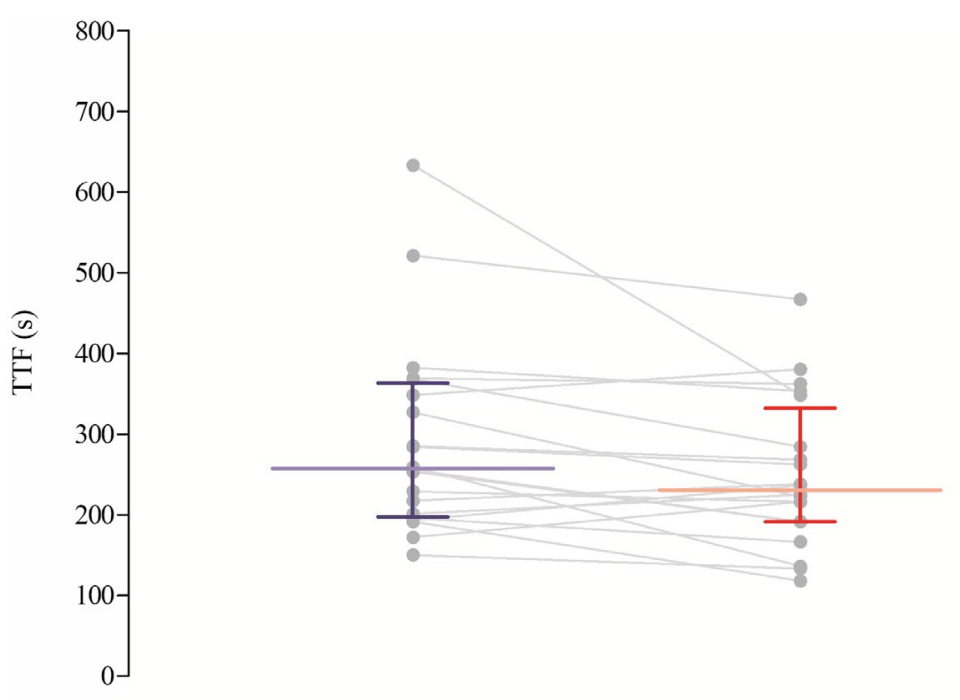

Control Prior HG

TABLE 1 Effort and affect ratings across the KE performance task

\begin{tabular}{llll} 
& \multicolumn{2}{l}{ Time } & \\
\cline { 2 - 4 } & $\mathbf{3 0 ~ s}$ & $\mathbf{6 0 ~ s}$ & TTF \\
\hline Effort & & & \\
Control & $3 \pm 1$ & $4 \pm 1$ & $10[9-10]$ \\
Prior HG & $4 \pm 2$ & $5 \pm 2$ & $10[9-10]$ \\
Affect & & & \\
Control & $2 \pm 2$ & $1 \pm 1$ & $-4[-5--2]$ \\
Prior HG & $1 \pm 2$ & $0 \pm 1$ & $-4[-5--3]$ \\
\hline
\end{tabular}

Note: Data presented as mean $\pm S D$ for variables analyzed with parametric models and $M d n[I Q R]$ for variables assessed using non-parametric analysis. $N=20$.

contrast, there was a small decrease in RoF following the control intervention $\left(t_{(19)}=2.99, p=.023 ; d_{\mathrm{av}}=-0.27\right)$, but RoF was elevated following the KE task $\left(t_{(19)}=-6.64\right.$, $\left.p<.001 ; d_{\mathrm{av}}=2.33\right)$. There was no difference between conditions prior to the respective interventions $\left(t_{(19)}=\right.$ $\left.0.96, p=.349 ; d_{\mathrm{av}}=-0.18\right)$, but RoF was greater in the prior HG condition immediately after the HG task $\left(t_{(19)}=\right.$ $\left.-9.53, p<.001 ; d_{\mathrm{av}}=2.88\right)$ and remained greater immediately after the KE task $\left(t_{(19)}=-8.15, p<.001 ; d_{\mathrm{av}}=0.69\right)$ (Figure 4).

\subsection{3 | Relationships between RoF, perceived effort, affect, and task performance}

Exploratory relationships between TTF and perceptual and affective variables (effort and affect at $60 \mathrm{~s}$, rate of change in effort and affect, RoF post-HG task) were

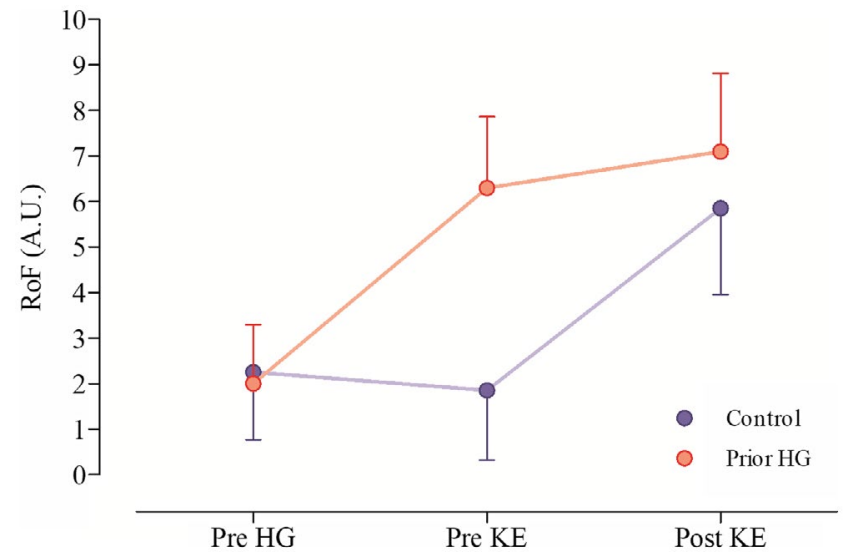

F I G U RE 4 Ratings of fatigue (RoF) across stages of the experimental protocol in both the prior handgrip (HG; red circles) and a control (blue circles) conditions. Ratings were collected pre HG (i.e., immediately prior to the handgrip task), pre KE (i.e., immediately prior to the knee extensor endurance task) and post KE (i.e., immediately after the knee extensor endurance task). $N=20$

consistent across conditions (Figure 5). TTF was negatively correlated with effort responses at $60 \mathrm{~s}$ (control: $r_{\mathrm{s}}$ $=-.72$, FDR-adjusted $p=.001$; prior HG: $r_{\mathrm{s}}=-.61, p=$ $.006)$ and positively correlated with affective valence at 60s (control: $r_{\mathrm{s}}=.68, p=.002$; prior HG: $r_{\mathrm{s}}=.46, p=$ .042). Rate of change in effort perception was also negatively associated with TTF (control: $r_{\mathrm{s}}=-.78, p<.001$; prior HG: $\left.r_{\mathrm{s}}=-.59, p=.008\right)$. However, both the rate of change in affect (control: $r_{\mathrm{s}}=-.26, p=.233$; prior HG: $\left.r_{\mathrm{s}}=-.03, p=.535\right)$ and RoF immediately preceding the start of the KE task (control: $r_{\mathrm{s}}=.12, p=.439$; prior HG: $r_{\mathrm{s}}=.11, p=.439$ ) were not correlated with TTF.

We next explored whether perceived fatigue ratings (RoF) were related to subsequent perceptual and affective 
F I G URE 5 Correlations between time to task failure (TTF) during the knee extensor (KE) endurance task and initial effort ratings (upper panel), initial affect ratings (middle panel), and the rate of change in effort perception (lower panel). Correlation coefficients are fitted for both the prior handgrip (HG; red circles) and control (blue circles) condition. $N=20$
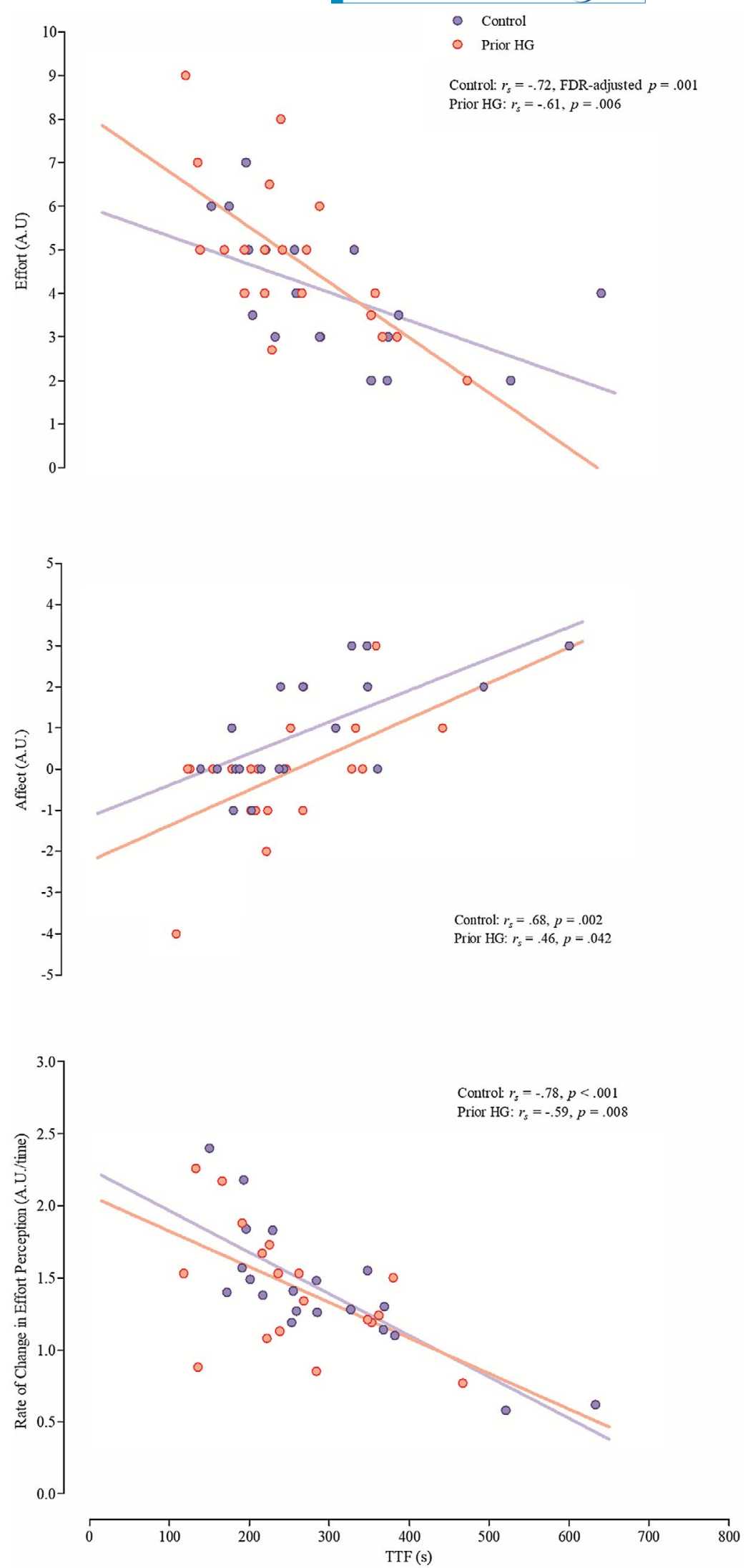

responses during (i.e., 60 s) motor activity. The repeated measures correlations demonstrated that RoF displayed a positive $\left(r_{\mathrm{rm}}=.60\right.$ [95\% CI: $\left.\left.0.25-0.80\right], p=.004\right)$ and negative $\left(r_{\mathrm{rm}}=-.68\right.$ [95\% CI: -0.51 to -0.87 ], $\left.p<.001\right)$ relationship with perceived effort and affective responses, respectively (Figure 6). 


\subsubsection{EMG responses during knee extension endurance task}

RMS EMG and MPF demonstrated a main effect of time, increasing $\left(F_{(2.7,48.8)}=21.94, p<.001, \eta_{p}^{2}=0.549\right)$ and decreasing $\left(F_{(3.5,59.1)}=33.82, p<.001, \eta_{p}^{2}=0.665\right)$ across the KE task, respectively. However, there was no main effect of condition $\left(\mathrm{RMS}: F_{(1,18)}=2.96, p=.103, \eta_{p}^{2}=0.141\right.$; MPF: $\left.F_{(1,17)}=0.32, p=.578, \eta_{p}^{2}=0.019\right)$ or interaction across isotime $\left(\mathrm{RMS}: F_{(2.7,48.5)}=0.60, p=.603, \eta_{p}^{2}=0.032\right.$; MPF: $\left.F_{(3.0,50.6)}=0.52, p=.666, \eta_{p}^{2}=0.030\right)$. RMS and MPF were not different between conditions at task termination (RMS: $t_{(18)}=0.46, p=.653, d_{\mathrm{av}}=-0.03 ; \mathrm{MPF}: t_{(17)}=-1.57$, $\left.p=.134, d_{\mathrm{av}}=0.23\right)$ (Figure 7).

\section{2 | Experiment two}

Repetitions and duration of the HG task performed by the sub-sample were similar to that observed in the whole sample in the first experiment $(11 \pm 3$ reps [range: $6-16$ reps]; $310.0 \pm 89.0 \mathrm{~s}$ [range: $170-470 \mathrm{~s}$ ]). Within the sub-sample, no difference was observed in the percentage change in $\mathrm{HG}$ MVC force of either the dominant $\left(t_{(14)}=1.50, p=.156, d_{\mathrm{av}}\right.$ $=-0.44)$ or the non-dominant $\left(t_{(14)}=0.56, p=.582, d_{\mathrm{av}}=\right.$ -0.18 ) hand between experiments.

\subsection{1 | Neuromuscular function of the KE following prior HG exercise}

Voluntary and evoked neuromuscular responses are shown in Table 2. Small reductions in voluntary force led to a main effect of time, with MVC declining across both conditions

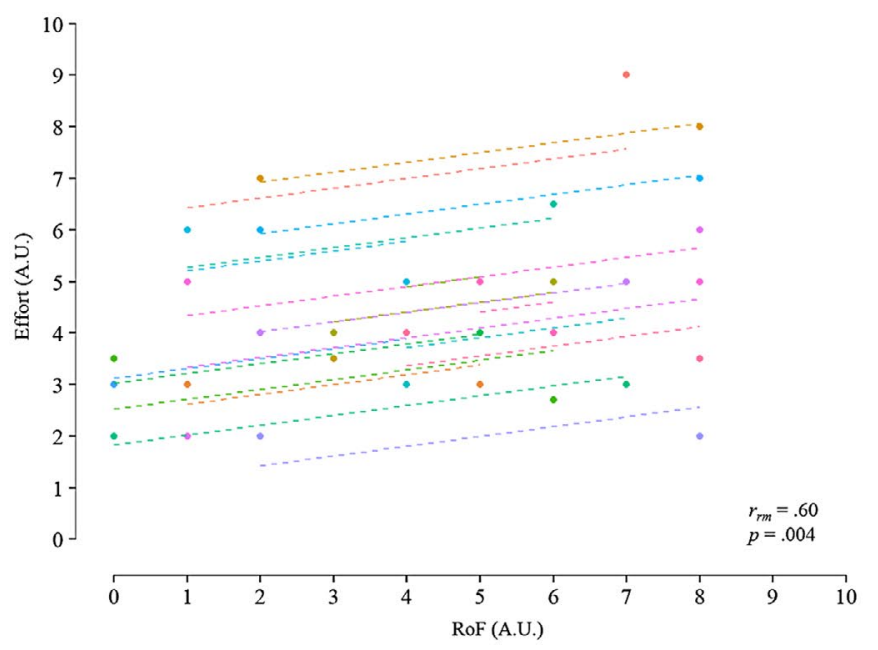

$\left(F_{(1,14)}=11.82, p=.004, \eta_{p}^{2}=0.458\right)$. MVC force was also significantly greater $\left(F_{(1,14)}=13.47, p=.003, \eta_{p}^{2}=0.490\right)$ in the control compared to the prior $\mathrm{HG}$ task (control: $555.5 \pm 84.7 \mathrm{~N}$; prior HG: $532.8 \pm 79.0 \mathrm{~N}$ ). Further investigation into this main effect of condition demonstrated that MVC force was different between the two conditions prior to the intervention $\left(t_{(14)}=2.87, p=.012, d_{\mathrm{av}}=-0.27\right)$. There was no interaction between condition and time for MVC force $\left(F_{(1,14)}=0.06, p=.808, \eta_{p}^{2}=0.004\right)$. The TOST procedure indicated that the observed effect in the change in MVC force between conditions $\left(d_{\mathrm{z}}=0.06\right)$ was not significantly within the prescribed bounds of equivalence $\left(d_{\mathrm{z}}=-0.39\right.$ and $\left.d_{\mathrm{z}}=0.39 ; t_{(14)}=-1.26, p=.113\right)$.

$Q_{\mathrm{tw}}$ decreased across interventions $\left(F_{(1,14)}=16.43\right.$, $p=.001, \eta_{p}^{2}=0.540$; pre: $147.3 \pm 22.0 \mathrm{~N}$ versus. post: $142.8 \pm 21.4 \mathrm{~N})$ and was also greater across the control condition $\left(F_{(1,14)}=18.09, p=.001, \eta_{p}^{2}=0.564\right.$; control: $149.8 \pm 18.8 \mathrm{~N}$; prior HG: $140.2 \pm 23.5 \mathrm{~N})$. Again, condition effects could be attributed to differences between conditions prior to the interventions $\left(t_{(14)}=3.66, p=.003, d_{\mathrm{av}}=-0.43\right)$. However, there was no interaction effect on $Q_{\mathrm{tw}}\left(F_{(1,14)}=\right.$ $\left.0.04, p=.846, \eta_{p}^{2}=0.003\right)$. The TOST procedure indicated that the observed effect $\left(d_{\mathrm{z}}=0.05\right)$ was not significantly within the prescribed bounds of equivalence $\left(d_{\mathrm{z}}=-0.05\right.$ and $\left.d_{\mathrm{z}}=0.05 ; t_{(14)}=-0.003, p=.499\right)$. No condition, time or interaction effects were observed for $M_{\max }$ responses (Table 2). The observed effect across interventions $\left(d_{\mathrm{z}}=-0.06\right)$ was not within prescribed equivalence bounds $\left(d_{\mathrm{z}}=-0.06\right.$ and $\left.d_{\mathrm{z}}=0.06 ; t_{(14)}=0.008, p=.503\right)$.

Changes across time were not evident for $\mathrm{VA}_{\mathrm{TMS}}\left(F_{(1,14)}\right.$ $\left.=2.64, p=.127, \eta_{p}^{2}=0.159\right)$ but voluntary activation was slightly lower in the prior $\mathrm{HG}$ condition $\left(F_{(1,14)}=10.46\right.$, $p=.006, \eta_{p}^{2}=0.428$; control: $95.9 \pm 2.9 \%$, prior $\mathrm{HG}$ : $94.1 \pm 3.7 \%)$. No interaction effect was found for $\mathrm{VA}_{\mathrm{TMS}}$

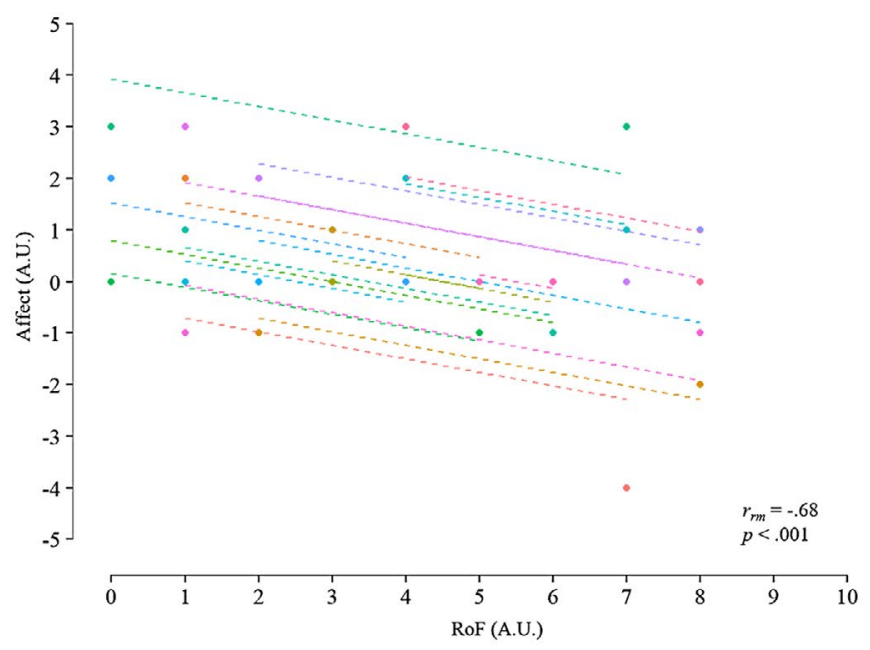

F I G URE 6 Repeated measures correlations between ratings of fatigue and initial effort (left panel) and initial affect (right panel). Observations from the same participant are represented by points of the same color. Corresponding dashed colored lines represent the repeated measures correlation fitted for each participant. $N=20$ 

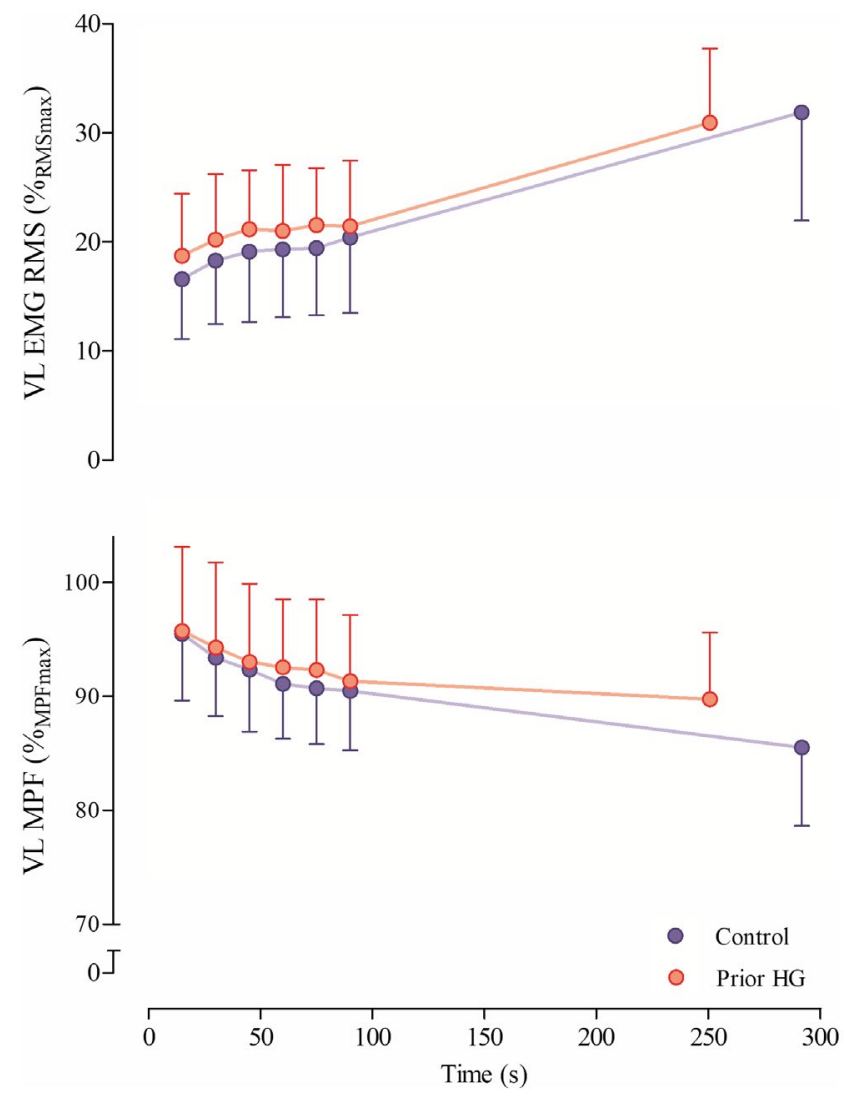

F I G U RE 7 Effect of prior handgrip (HG) task on the root mean square (RMS) EMG (upper panel) and mean power frequency (MPF) (lower panel) of the vastus lateralis (VL) during the KE endurance task following both prior HG (red circles) and control (blue circles) conditions. Values are expressed relative to responses recorded during maximal contractions preintervention. $N=19$

$\left(F_{(1,14)}=3.93, p=.067, \eta_{p}^{2}=0.219\right)$. The TOST procedure demonstrated that the effect between conditions in the change in $\mathrm{VA}_{\mathrm{TMS}}\left(d_{\mathrm{z}}=0.51\right)$ was not significantly within the bounds of equivalence $\left(d_{\mathrm{z}}=-0.26\right.$ and $d_{\mathrm{z}}=0.26 ; t_{(14)}=0.977, p$ $=.827)$. Greater $\operatorname{SIT}_{100 \%}$ force was evident in the prior HG condition $\left(F_{(1,14)}=5.42, p=.035, \eta_{p}^{2}=0.279\right.$; control: $1.00 \pm 0.80 \%_{\mathrm{MVC}}$; prior HG: $1.25 \pm 0.88 \%_{\mathrm{MVC}}$ ) but no time $\left(F_{(1,14)}=1.87, p=.193, \eta_{p}^{2}=0.118\right)$ or interaction effects were evident $\left(F_{(1,14)}=4.44, p=.054, \eta_{p}^{2}=0.241\right)$. The effect in the change in SIT $_{100 \%}$ between conditions $\left(d_{\mathrm{z}}=-0.55\right)$ was not significantly within the bounds of equivalence $\left(d_{\mathrm{z}}=\right.$ -0.38 and $\left.d_{\mathrm{z}}=0.38 ; t_{(14)}=-0.636, p=.732\right)$.

Agonist MEP amplitudes $\left(\% M_{\max }\right)$ evoked in the KE are presented in Table 3. Irrespective of volitional contraction intensity, corticospinal excitability was unchanged by both condition $\left(F=0.04-1.36\right.$, all $\left.p>.05, \eta_{p}^{2}=0.003-0.089\right)$ and time $\left(F=0.11-3.21\right.$, all $\left.p>.05, \eta_{p}^{2}=0.008-0.187\right)$. Background EMG RMS, recorded immediately prior to stimulation, was unaffected by the experimental manipulations (all $p>.05$ ), while antagonist BF MEP responses were also unchanged (all $p>.05$ ) (Data for antagonist MEP responses and background

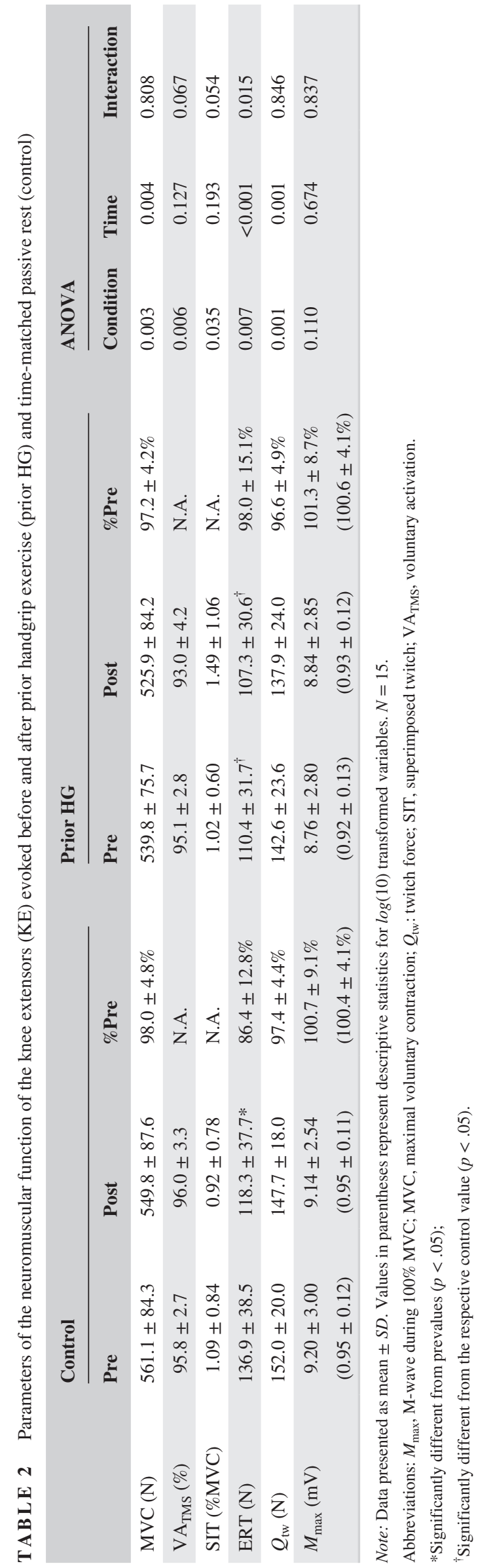


TA B LE 3 Motor evoked potentials (MEPs; \% $M_{\max }$ ) recorded in the vastus lateralis (VL) at both relative and absolute force levels

\begin{tabular}{|c|c|c|c|c|c|c|c|}
\hline \multirow[b]{2}{*}{ Force } & \multicolumn{2}{|l|}{ Control } & \multicolumn{2}{|l|}{ Prior HG } & \multicolumn{3}{|l|}{ ANOVA } \\
\hline & Pre & Post & Pre & Post & Condition & Time & Interaction \\
\hline $87.5 \%$ & $40.7 \pm 12.8$ & $40.5 \pm 10.3$ & $39.8 \pm 10.6$ & $41.9 \pm 10.4$ & 0.853 & 0.611 & 0.546 \\
\hline $75 \%$ & $43.7 \pm 10.2$ & $42.5 \pm 11.6$ & $40.9 \pm 11.1$ & $40.2 \pm 10.5$ & 0.263 & 0.656 & 0.860 \\
\hline $20 \%_{\mathrm{B}}$ & $49.6 \pm 13.2$ & $44.3 \pm 14.8$ & $46.4 \pm 11.8$ & $49.3 \pm 14.2$ & 0.549 & 0.208 & 0.060 \\
\hline
\end{tabular}

Note: Data presented as mean $\pm S D .20 \%_{\mathrm{B}}$ : Absolute force value $(126.5 \pm 18.6 \mathrm{~N})$ equating to $20 \%$ of preliminary maximal force production. $N=15$.

RMS EMG are not shown). At an absolute force level (20\% $\%_{B}$ : $126.5 \pm 18.6 \mathrm{~N}$ ), corticospinal excitability was unchanged (Table 3). Evoked antagonist responses at $20 \%_{\mathrm{B}}$ were also unaffected (interaction: $F_{(1,14)}=0.68, p=.425, \eta_{p}^{2}=0.046$; condition: $F_{(1,14)}=0.73, p=.408, \eta_{p}^{2}=0.049$; time: $F_{(1,14)}<$ $\left.0.01, p=.979, \eta_{p}^{2}<0.001\right)$. All observed effects in the change in MEP response between conditions were not deemed equivalent (all $p>.05)$.

\section{4 | DISCUSSION}

In the first experiment, we used prior remote exercise in the upper body to study the interactions between perceptions of fatigue, effort, and affect during a sustained, sub-maximal contraction of the KE. As hypothesized, impaired KE endurance performance was associated with increased perceptions of effort and reduced affect. Perceptions of fatigue were also increased by the HG exercise, but perceptions of fatigue were not correlated with KE endurance performance. Perceptions of fatigue were, however, correlated with effort and affective ratings during the endurance exercise. In the second experiment, the absence of interaction effects suggests that maximal force production, voluntary activation, and corticospinal responses of the KE were not influenced directly by the performance of prior $\mathrm{HG}$ exercise. We cautiously interpret our findings to indicate no difference in recorded neuromuscular function between conditions. These results indicate that $\operatorname{cog}$ nitive-emotional interactions limit endurance performance, independent of acute alterations to neuromuscular function.

Termination of endurance performance is limited by the attainment of maximal perceived effort, which has been associated with either homeostatic threat (Noakes, 2012) or more general motivational processes (Marcora, 2008). In the present study, effort perception was increased following the HG exercise compared to the control condition. The correlations between TTF and the rate of change in effort perception across both conditions suggest that this increased effort perception induced by the HG exercise caused faster attainment of maximal effort. Our results support previous observations in both single limb and whole-body exercise, demonstrating increased effort perception following prior remote exercise independent of concomitant changes in the neuromuscular function (Amann et al., 2013; Johnson et al., 2015; Morgan et al., 2019). The results of the present study also parallel those observed following prior cognitive tasks (Pageaux et al., 2013; Pageaux, Marcora, Rozand, \& Lepers, 2015) which may support the proposal that prior cognitive activity and remote motor exercise increase effort and limit subsequent motor performance through shared processes within the brain (Pageaux \& Lepers, 2016). The absence of neuromuscular impairment suggests that heightened effort perception was unlikely a response to compensatory increases in motor output (and thus corollary discharge) from motor centers (de Morree et al., 2012; Marcora et al., 2008). An alternative explanation may be that prior neural activity during the HG exercise elicited changes in sensorimotor regions and the processing of corollary discharges during the KE endurance task (Pageaux \& Lepers, 2016). However, the present study was not equipped to investigate this hypothesis.

Affective valence was also reduced by prior HG exercise and affective responses were related to task performance across conditions. Our data, therefore, indicate both effort perception and affective valence are important for behavioral regulation during motor activity. Challenges to homeostasis are sensed within interoceptive circuits and are intrinsically valenced (Lindquist, Satpute, Wager, Weber, \& Barrett, 2016). Homeostatic challenges thus evoke affective changes, which may disrupt current goal-related actions and influence decision making in favor of more biologically significant behaviors, that is, the preservation of homeostasis (Damasio \& Carvalho, 2013). Unsurprisingly then, affect has previously been associated with endurance performance (Hartman et al., 2019; Jones et al., 2015; Renfree, West, Corbett, Rhoden, \& Gibson, 2012). Hartman et al. (2019) proposed that during intense exercise, the perception of effort is intrinsically affective, such that the two constructs merge, with the experience of intense displeasure enabling the sense of effort to enter consciousness and ultimately lead to the termination of the activity. This may explain why both effort and affect were related to endurance performance within the present study. However, unlike effort, the rate of change of affect was not associated 
with task termination which may question the validity of this proposition. Further studies are required not only to further distinguish the behavioral influence of both effort and affective valence, but also clearly differentiate the two constructs.

Prior motor activity also led to greater subjective RoF. Though not correlated with the performance itself, perceptions of fatigue were associated with initial effort and affective responses during the KE endurance task. Our findings support recent observations following prior cognitive activity (Harris \& Bray, 2019) and are also in line within findings within clinical populations (Prak et al., 2019). Disassociation of perceptions of fatigue, effort, and affect may be inherently difficult since all may reflect outcomes of the same integrated control process (Hockey, 2011). However, we appear to have been able to, at least partially, disassociate fatigue from perceptual/affective regulatory responses to endurance exercise, evidenced not only through different behavioral correlates but also the intensity of the responses. While effort and affect were (or close to) maximal and minimal, at task failure in both conditions, respectively, perceptions of fatigue were distinctly sub-maximal and differed between conditions.

Recent metacognitive theories of fatigue may provide a framework to understand the observed relationships between the studied perceptual and affective responses. Within these theories, fatigue reflects a concern (or negative belief) in one's ability to control (or predict) bodily states (Manjaly et al., 2019; Stephan et al., 2016). The perception of effort (Kuppuswamy, 2017) and core affect (Barrett, 2017) have been proposed to emerge through a mismatch (i.e., prediction error) between the predicted proprioceptive/interoceptive sensory consequences of action and the actual sensory feedback received. Prediction error increases attention towards ascending sensory information and conscious awareness of perceptual and affective changes, which may undermine belief in held internal models generating control predictions (Stephan et al., 2016). Declines in confidence (or precision) in issued proprioceptive/interoceptive predictions (that is, fatigue) may, therefore, lead to greater prediction errors and attention towards ascending sensory information in lower parts of the system, which further influence perceptual responses to action (i.e., increasing perceived effort and reducing affect). Our findings appear to support the structure of these metacognitive theories and implicate fatigue within an overarching control of the psychophysiological regulation of endurance performance. As the RoF does not capture the hedonic properties of fatigue (Micklewright et al., 2017), it is possible that the association between affect and fatigue simply reflects the emotional component of the fatigue perceptions (St Clair Gibson et al., 2003). However, that the two constructs could be at least partially disassociated would appear to suggest otherwise. In line with metacognitive propositions, we suggest that the perception of fatigue sits above lower-level perceptual (e.g., effort) and affective responses and modulates the attention afforded to ascending prediction errors within proprioceptive/interoceptive systems (i.e., how much effort is required and/or the affective responses evoked through physiological perturbations), which in turn influence action. Further, larger-scale investigations analyzing the mediating effect of the perception of fatigue may enable the assessment of this hypothesis.

In experiment two, the prior HG exercise did not significantly alter neuromuscular responses of the rested dominant KE. All interaction effects between condition and time were non-significant. Though changes in parameters fell outside the estimated bounds of equivalence, we cautiously interpret our findings to demonstrate no significant effect of prior $\mathrm{HG}$ exercise on KE neuromuscular function. The findings add to a growing number of observations describing no functional effects (i.e., loss of force) across the upper and lower body within non-activated, heterologous muscle groups following both whole-body (Decorte, Lafaix, Millet, Wuyam, \& Verges, 2012; Ross, Middleton, Shave, George, \& Nowicky, 2007) and single-limb exercise (Aboodarda, Copithorne, Power, Drinkwater, $\&$ Behm, 2015; Aboodarda et al., 2017). It appears that, following prior remote exercise, cortical motor output is well maintained during brief contractions. Where evidenced, force deficits evoked by prior, remote exercise have primarily been observed in anticipation of $(\mathrm{Li}$, Power, Marchetti, \& Behm, 2019) or toward the end of the protracted or repeated activity (Halperin, Aboodarda, \& Behm, 2014). Based on the outcomes of experiment one, it is possible that such declines may simply reflect changes in motivational and decision-making processes determining the allocation of effort (e.g., Meyniel, Sergent, Rigoux, Daunizeau, \& Pessiglione, 2013) rather than direct physiological inhibitory feedback mechanisms.

The corticospinal excitability of the KE was also unchanged by the prior HG task. To the best of our knowledge, the present study represents the first quantification of MEPs in the lower limbs following prior exercise in the upper limbs. Conflicting responses have been reported in the elbow flexors following lower limb activity (Aboodarda et al., 2017; Šambaher et al., 2016; Sidhu et al., 2014). Aboodarda et al. (2017) reported that effects to the supra-spinal excitability of the elbow flexors were force dependent, with an increase in the ratio of corticospinal to spinal motoneuronal responses evident at 100\% MVC, no change evident at 50\% MVC and a decrease observed at 5\% MVC. The discrepancy between these results and those of the present study may be attributed to various methodological differences (e.g., stimulator intensity; McNeil, Giesebrecht, Gandevia, \& Taylor, 2011). Of particular interest may be differences between upper and lower limb neurophysiology. Stronger connectivity between pre-motor and primary motor cortex has previously been reported during the activity of the upper limbs compared to the lower limbs (Volz, Eickhoff, Pool, Fink, \& Grefkes, 2015). Increased connectivity between premotor areas and M1 in order to facilitate or maintain motor output during demanding activity (Jiang, Wang, Kisiel-Sajewicz, Yan, \& 
Yue, 2012) may, therefore, be more effective in non-exercised upper limb muscles, leading to greater MEP facilitation at maximal force intensities in the upper limbs. We did not measure the excitability of the spinal motoneuron pool so could not evaluate the excitability of supra-spinal circuitries specifically, which appear the most likely site of effects within non-activated muscles (Aboodarda et al., 2017; Šambaher et al., 2016). Increased motoneuron excitability of the KE has been reported following sustained maximal contractions of the elbow flexors (Aboodarda et al., 2015). As the total excitability of the corticospinal tract is the product of both supra-spinal and spinal influences, we cannot discount that supra-spinal excitability of the KE motoneurons may have in fact seen a relative reduction. Future research is thus required to further quantify the supra-spinal excitability of the lower limbs following prior upper body motor activity.

Some methodological limitations of the present study should also be considered: First, we treated our perceptual and affective ratings as continuous, rather than ordinal variables (e.g., Bishop $\&$ Herron, 2015), adopting parametric factorial analyses. It is suggested that, due to the length of the scales used, such an approach may be justified (Harpe, 2015). However, as debate concerning the most appropriate statistical analysis of this form of data continues (Carifio \& Perla, 2008; Knapp, 1990), we urge interested parties to reanalyze our data as they see fit (https://osf.io/kbzvn ). Next, it is important to acknowledge that RoF was assessed at rest, while effort and affect were measured during the KE task. Unlike effort perception, fatigue ratings are not inherently dependent upon motor signals (Micklewright et al., 2017), however, the disassociation of response intensity and behavioral correlates between fatigue and effort/affect may have been influenced by the absence of central motor commands when assessing fatigue. In experiment two, the main effects of condition for voluntary and evoked contractions were evident, with lower responses recorded in the prior HG condition. This reduction could account for the altered perceptual and affective responses of experiment one. Importantly, deficits were evident between conditions prior to the respective interventions. As conditions were performed in a constant order, this most likely represents an effect of order or time. Moreover, the reductions were small ( 4\%-6\%) and within the typical error associated with these measures at rest and therefore we believe do not represent an acute effect of prior remote activity (Dekerle et al., 2019). Replication studies of the presented effects are required. Finally, at least six stimulations have been recommended for the reliable assessment of corticospinal excitability (Lewis, Signal, \& Taylor, 2014).

\section{5 | CONCLUSION}

In conclusion, we provide evidence that prior, remote exercise may be used as an effective paradigm in isolating and studying the interactions between perceptual and affective factors and associated consequences to physical endurance performance. When preceded by demanding exercise in the upper limbs, lower body endurance performance is limited through complex cognitive-emotional interactions, independent of acute challenges to the integrity of the neuromuscular system. While effort and affective responses were shown to be associated with the termination of endurance performance specifically, perceptions of fatigue were implicated in performance regulation indirectly, through an overarching control of these perceptual and affective constructs.

\section{REPRINTS}

Mr. A Greenhouse-Tucknott (A.Greenhouse-Tucknott@ brighton.ac.uk).

\section{ACKNOWLEDGMENTS}

The authors would like to thank Dr. L Schäfer, Dr. N Smeeton, and Dr. M Hayes for their valued discussion during the design of this study. The authors would also like to extend our thanks to Dr. R Souron for his advice on TMS protocol. The authors also like to thank the volunteers who participated.

\section{CONFLICT OF INTERESTS}

No competing interests declared.

\section{AUTHOR CONTRIBUTIONS}

All authors were involved in the design of the study. AGT and MR performed the data collection. AGT drafted the first version of the manuscript, with all authors involved in subsequent revisions and approval of the final document.

\section{ORCID}

A. Greenhouse-Tucknott (D) https://orcid. org/0000-0002-9257-521X

J. G. Wrightson (D) https://orcid.org/0000-0001-7106-7470

N. A. Harrison (D) https://orcid.org/0000-0002-9584-3769

J. Dekerle (D) https://orcid.org/0000-0002-4482-4576

\section{REFERENCES}

Aboodarda, S. J., Copithorne, D. B., Power, K. E., Drinkwater, E., \& Behm, D. G. (2015). Elbow flexor fatigue modulates central excitability of the knee extensors. Applied Physiology, Nutrition and Metabolism, 40(9), 924-930. https://doi.org/10.1139/ apnm-2015-0088

Aboodarda, S. J., Šambaher, N., Millet, G. Y., \& Behm, D. G. (2017). Knee extensors neuromuscular fatigue changes the corticospinal pathway excitability in biceps brachii muscle. Neuroscience, 340, 477-486. https://doi.org/10.1016/j.neuroscience.2016.10.065

Amann, M., Venturelli, M., Ives, S., McDaniel, J., Layec, G., Rossman, M. J., \& Richardson, R. S. (2013). Peripheral fatigue limits endurance exercise via a sensory feedback-mediated reduction in spinal motoneuronal output. Journal of Applied Physiology, 115(3), 355364. https://doi.org/10.1152/japplphysiol.00049.2013 
Bakdash, J. Z., \& Marusich, L. R. (2017). Repeated measures correlation. Frontiers in Psychology, 8, 456. https://doi.org/10.3389/ fpsyg.2017.00456

Bangsbo, J., Madsen, K., Kiens, B., \& Richter, E. A. (1996). Effect of muscle acidity on muscle metabolism and fatigue during intense exercise in man. Journal of Physiology, 495(2), 587-596. https://doi. org/10.1113/jphysiol.1996.sp021618

Barbosa, T. C., Vianna, L. C., Fernandes, I. A., Prodel, E., Rocha, H. N. M., Garcia, V. P., ... Nobrega, A. C. L. (2016). Intrathecal fentanyl abolishes the exaggerated blood pressure response to cycling in hypertensive men. Journal of Physiology, 594, 715-725. https://doi. org/10.1113/JP271335

Barrett, L. F. (2017). The theory of constructed emotion: An active inference account of interoception and categorization. Social Cognitive and Affective Neuroscience, 12(1), 1-23. https://doi.org/10.1093/ scan/nsw154

Benjamini, Y., \& Yosef, H. (2000). On the adaptive control of the false discovery rate in multiple testing with independent statistics. Journal of Educational and Behavioral Statistics, 25(1), 60-83. https://doi.org/10.3102/10769986025001060

Bishop, P. A., \& Herron, R. L. (2015). Use and misuse of the Likert item responses and other ordinal measures. International Journal of Exercise Science, 8(3), 297-302.

Borg, G. (1982). The psychophysical bases of perceived exertion. Medicine \& Science in Sports \& Exercise, 14(5), 377-381. https:// doi.org/10.1249/00005768-198205000-00012

Borg, G. (1986). Psychophysical studies of effort and exertion: Some historical, theoretical and empirical aspects. In G. Borg \& D. Ottoson (Eds.), The perception of exertion in physical work (pp. 3-12). New York, NY: Macmillan. https://doi.org/10.1007/978-1349-08946-8_1

Broxterman, R. M., Hureau, T. J., Layec, G., Morgan, D. E., Bledsoe, A. D., Jessop, J. E., ... Richardson, R. S. (2018). Influence of group III/IV muscle afferents on small muscle mass exercise performance: A bioenergetics perspective. Journal of Physiology, 596(12), 23012314. https://doi.org/10.1113/JP275817

Broxterman, R. M., Layec, G., Hureau, T. J., Morgan, D. E., Bledsoe, A. D., Jessop, J. E., ... Richardson, R. S. (2017). Bioenergetics and ATP synthesis during exercise: Role of group III/IV muscle afferents. Medicine and Science in Sports and Exercise, 49(12), 24042413. https://doi.org/10.1249/MSS.0000000000001391

Carifio, J., \& Perla, R. (2008). Resolving the 50-year debate around using and misusing Likert scales. Medical Education, 42(12), 11501152. https://doi.org/10.1111/j.1365-2923.2008.03172.x

Christian, R. J., Bishop, D. J., Billaut, F., \& Girard, O. (2014). The role of sense of effort on self-selected cycling power output. Frontiers in Physiology, 5, 115. https://doi.org/10.3389/fphys.2014.00115

Craig, A. D. (2002). How do you feel? Interoception: The sense of the physiological condition of the body. Nature Reviews Neuroscience, 3(8), 655-666. https://doi.org/10.1038/nrn894

Damasio, A., \& Carvalho, G. B. (2013). The nature of feelings: Evolutionary and neurobiological origins. Nature Reviews Neuroscience, 14(2), 143-152. https://doi.org/10.1038/nrn3403

de Lima, F. D., Bottaro, M., de Oliveiera Valeriano, R., Cruz, L., Battalini, C. L., Vieira, C. A., \& de Oliveira, R. J. (2018). Cancerrelated fatigue and muscle quality in Hodgkin's lymphoma survivors. Integrated Cancer Therapies, 17(2), 299-305. https://doi. org/10.1177/1534735417712009

de Morree, H. M., Klein, C., \& Marcora, S. M. (2012). Perception of effort reflects central motor command during movement execution.
Psychophysiology, 49, 1242-1253. https://doi.org/10.1016/j.ijpsy cho.2012.06.042

Decorte, N., Lafaix, P. A., Millet, G. Y., Wuyam, B., \& Verges, S. (2012). Central and peripheral fatigue kinetics during exhaustive constant-load cycling. Scandinavian Journal of Medicine and Science in Sports, 22(3), 381-391. https://doi. org/10.1111/j.1600-0838.2010.01167.x

Dekerle, J., Greenhouse-Tucknott, A., Wrightson, J. G., Schäfer, L., \& Ansdell, P. (2019). Improving the measurement of TMS-assessed voluntray activation in the knee extensors. PLoS One, 14(6), e0216981. https://doi.org/10.1371/journal.pone.0216981

Doix, A.-C.-M., Lefèvre, F., \& Colson, S. S. (2013). Time course of the cross-over effect of fatigue on the contralateral muscle after unilateral exercise. PLoS One, 8(5), e64910. https://doi.org/10.1371/journ al.pone.0064910

Doix, A.-C.-M., Wachholz, F., Marterer, N., Immler, L., Insam, K., \& Federolf, P. A. (2018). Is the cross-over effect of a unilateral high-intensity leg extension influenced by the sex of the participants? Biology of Sex Differences, 9, 29. https://doi.org/10.1186/s1329 3-018-0188-4

Dunaway Young, S., Montes, J., Kramer, S. S., Podwika, B., Rao, A. K., \& De Vivo, D. C. (2019). Perceived fatigue in spinal muscular atrophy: A pilot study. Journal of Neuromuscular Disorders, 6(1), 109-117. https://doi.org/10.3233/JND-180342

Gruet, M., Temesi, J., Rupp, T., Levy, P., Verges, S., \& Millet, G. Y. (2014). Dynamics of corticospinal changes during and after a high-intensity quadriceps exercise. Experimental Physiology, 99(8), 1053-1064. https://doi.org/10.1113/expph ysiol.2014.078840

Halperin, I., Aboodarda, S. J., \& Behm, D. G. (2014). Knee extension fatigue attenuates repeated force production of the elbow flexors. European Journal of Sport Science, 14(8), 823-829. https://doi. org/10.1080/17461391.2014.911355

Halperin, I., Chapman, D. W., \& Behm, D. G. (2015). Non-local muscle fatigue: Effects and possible mechanisms. European Journal of Applied Physiology, 115(10), 2031-2048. https://doi.org/10.1007/ s00421-015-3249-y

Halperin, I., \& Emanuel, A. (2020). Rating of perceived effort: Methodological concerns and future directions. Sports Medicine, 50, 679-687. https://doi.org/10.1007/s40279-019-01229-z

Hardy, C. J., \& Rejeski, W. J. (1989). Not what, but how one feels: The measurement of affect during exercise. Journal of Sport \& Exercise Psychology, 11, 304-317. https://doi.org/10.1123/ jsep.11.3.304

Harpe, S. E. (2015). How to analyze Likert and other rating scale data. Currents in Pharmacy Teaching and Learning, 7(6), 836-850. https://doi.org/10.1016/j.cptl.2015.08.001

Harris, S., \& Bray, S. R. (2019). Effects of mental fatigue on exercise decision-making. Psychology of Sport and Exercise, 44, 1-8. https:// doi.org/10.1016/j.psychsport.2019.04.005

Hartman, M. E., Ekkekakis, P., Dicks, N. D., \& Pettitt, R. W. (2019). Dynamics of pleasure-displeasure at the limit of exercise tolerance: Conceptualizing the sense of exertional physical fatigue as an affective response. Journal of Experimental Biology, 222, jeb186585. https://doi.org/10.1242/jeb.186585

Hermens, H. J., Freriks, B., Disselhorst-Klug, C., \& Rau, G. (2000). Development of recommendations for SEMG sensors and sensor placement procedures. Journal of Electromyography and Kinesiology, 10(5), 361-374. https://doi.org/10.1016/S1050 $-6411(00) 00027-4$ 
Hockey, G. R. J. (2011). A motivational control theory of cognitive fatigue. In P. L. Ackerman (Ed.), Cognitive fatigue: Multidisciplinary perspectives on current research and future applications (pp. 167-188). Washington, DC: American Psychological Association. https://doi.org/10.1037/12343-008

Jiang, Z., Wang, X. F., Kisiel-Sajewicz, K., Yan, J. H., \& Yue, G. H. (2012). Strengthened functional connectivity in the brain during muscle fatigue. NeuroImage, 60(1), 728-737. https://doi. org/10.1016/j.neuroimage.2011.12.013

Johnson, M. A., Sharpe, G. R., Williams, N. C., \& Hannah, R. (2015). Locomotor muscle fatigue is not critically regulated after prior upper body exercise. Journal of Applied Physiology, 119(7), 840850. https://doi.org/10.1152/japplphysiol.00072.2015

Jones, H. S., Williams, E. L., Marchant, D., Sparks, S. A., Midgley, A. W., Bridge, C. A., \& McNaughton, L. (2015). Distance-dependent association of affect with pacing strategy in cycling time trials. Medicine and Science in Sports and Exercise, 47(4), 825-832. https://doi.org/10.1249/MSS.0000000000000475

Kennedy, A., Hug, F., Sveistrup, H., \& Guével, A. (2013). Fatiguing handgrip exercise alters maximal force-generating capacity of plantar-flexors. European Journal of Applied Physiology, 113(3), 559566. https://doi.org/10.1007/s00421-012-2462-1

Knapp, T. R. (1990). Treating ordinal scales as interval scales: An attempt to resolve the controversy. Nursing Research, 39(2), 121-123. https://doi.org/10.1097/00006199-199003000-00019

Kuppuswamy, A. (2017). The fatigue conundrum. Brain, 140(8), 22402245. https://doi.org/10.1093/brain/awx153

Lakens, D. (2013). Calculating and reporting effect sizes to facilitate cumulative science: A practical primer for $\mathrm{t}$-tests and ANOVAs. Frontiers in Psychology, 4, 863. https://doi.org/10.3389/ fpsyg.2013.00863

Lakens, D. (2017). Equivalence tests: A practical primer for t tests, correlations, and meta-analyses. Social Psychological and Personality Science, 8(4), 355-362. https://doi.org/10.1177/1948550617697177

Lampropoulou, S. I., \& Nowicky, A. V. (2014). Perception of effort changes following an isometric fatiguing exercise of elbow flexors. Motor Control, 18(2), 146-164. https://doi.org/10.1123/ mc.2013-0010

Lewis, G. N., Signal, N., \& Taylor, D. (2014). Reliability of lower limb motor evoked potentials in stroke and healthy populations: How many responses are needed? Clinical Neurophysiology, 125(4), 748-754. https://doi.org/10.1016/j.clinph.2013.07.029

Li, Y., Power, K. E., Marchetti, P. H., \& Behm, D. G. (2019). The effect of dominant first dorsal interosseous fatigue on the force production of a contralateral homologous and heterologous muscle. Applied Physiology, Nutrition and Metabolism, 44(7), 704-712. https://doi. org/10.1139/apnm-2018-0583

Lindquist, K. A., Satpute, A. B., Wager, T. D., Weber, J., \& Barrett, L. F. (2016). The brain basis of positive and negative affect: Evidence from a meta-analysis of the human neuroimaging literature. Cerebral Cortex, 26, 1910-1922. https://doi.org/10.1093/ cercor/bhv001

Loy, B. D., Taylor, R. L., Fling, B. W., \& Horak, F. B. (2017). Relationship between perceived fatigue and performance fatigability in people with Multiple Sclerosis: A systematic review and meta-analysis. Journal of Psychosomatic Research, 100, 1-7. https:// doi.org/10.1016/j.jpsychores.2017.06.017

Manjaly, Z.-M., Harrison, N. A., Critchley, H. D., Do, C. T., Stefanics, G., Wenderoth, N., ... Stephan, K. E. (2019). Pathophysiological and cognitive mechanisms of fatigue in multiple sclerosis. Journal of Neurology, Neurosurgery \& Psychiatry, 90(6), 642-651. https:// doi.org/10.1136/jnnp-2018-320050

Marcora, S. M. (2008). Do we really need a central governor to explain brain regulation of exercise performance? European Journal of Applied Physiology, 104(5), 929-931. https://doi.org/10.1007/ s00421-008-0818-3

Marcora, S. M. (2009). Perception of effort during exercise is independent of afferent feedback from skeletal muscles, heart, and lungs. Journal of Applied Physiology, 106, 2060-2062. https://doi. org/10.1152/japplphysiol.90378.2008

Marcora, S. M. (2010). Effort: Perception of. In E. B. Goldstein (Ed.), Encyclopedia of perception (pp. 380-383). Thousand Oaks, CA: Sage. https://doi.org/10.4135/9781412972000.n119

Marcora, S. M., Bosio, A. B., \& de Morree, H. M. (2008). Locomotor muscle fatigue increases cardiorespiratory responses and reduces performance during intense cycling exercise independently from metabolic stress. American Journal of Physiology - Regulatory, Integrative and Comparative Physiology, 294(3), R874-R883. https://doi.org/10.1152/ajpregu.00678.2007

Marcora, S. M., \& Staiano, W. (2010). The limit to exercise tolerance in humans: Mind over muscle? European Journal of Applied Physiology, 109(4), 763-770. https://doi.org/10.1007/s0042 1-010-1418-6

McNeil, C. J., Giesebrecht, S., Gandevia, S. C., \& Taylor, J. L. (2011). Behaviour of the motoneurone pool in a fatiguing submaximal contraction. Journal of Physiology, 589(14), 3533-3544. https://doi. org/10.1113/jphysiol.2011.207191

Meyniel, F., Sergent, C., Rigoux, L., Daunizeau, J., \& Pessiglione, M. (2013). Neurocomputational account of how the human brain decides when to have a break. Proceedings of the National Academy of Sciences of the United States of America, 110(7), 2641-2646. https://doi.org/10.1073/pnas.1211925110

Micklewright, D., St Clair Gibson, A., Gladwell, V., \& Al Salman, A. (2017). Development and validity of the rating-of-fatigue scale. Sports Medicine, 47(11), 2375-2393. https://doi.org/10.1007/s4027 9-017-0711-5

Mitchell, J. H., Reeves, D. R., Rogers, H. B., \& Secher, N. H. (1989). Epidural anaesthesia and cardiovascular responses to static exercise in man. Journal of Physiology, 417, 13-24. https://doi.org/10.1113/ jphysiol.1989.sp017787

Morgan, P. T., Bailey, S. J., Banks, R. A., Fulford, J., Vanhatalo, A., \& Jones, A. M. (2019). Contralateral fatigue during severe-intensity single-leg exercise: Influence of acute acetaminophen ingestion. American Journal of Physiology - Regulatory, Integrative and Comparative Physiology, 317, R346-R354. https://doi.org/10.1152/ ajpregu.00084.2019

Mosso, A. (1891). La Fatica. Hollywood, AL: Treves.

Noakes, T. D. (2012). Fatigue is a brain-derived emotion that regulates the exercise behavior to ensure the protection of whole body homeostasis. Frontiers in Physiology, 3, 82. https://doi.org/10.3389/ fphys.2012.00082

Nordsborg, N., Mohr, M., Pedersen, L. D., Nielsen, J. J., Langberg, H., \& Bangsbo, J. (2003). Muscle interstitial potassium kinetics during intense exhaustive exercise: Effect of previous arm exercise. American Journal of Physiology - Regulatory, Integrative and Comparative Physiology, 285, 143-148. https://doi.org/10.1152/ ajpregu.00029.2003

Oldfield, R. C. (1971). The assessment and analysis of handedness: The Edinburgh Inventory. Neuropsychologia, 9(1), 97-113. https://doi. org/10.1016/0028-3932(71)90067-4 
Pageaux, B., \& Gaveau, J. (2016). Studies using pharmacological blockade of muscle afferents provide new insights into the neurophysiology of perceived exertion. Journal of Physiology, 594(18), 5049-5051. https://doi.org/10.1113/JP272585

Pageaux, B., \& Lepers, R. (2016). Fatigue induced by physical and mental exertion increases perception of effort and impairs subsequent endurance performance. Frontiers in Physiology, 7, 587. https://doi. org/10.3389/fphys.2016.00587

Pageaux, B., Marcora, S. M., \& Lepers, R. (2013). Prolonged mental exertion does not alter neuromuscular function of the knee extensors. Medicine and Science in Sports and Exercise, 45(12), 2254-2264. https://doi.org/10.1249/MSS.0b013e31829b504a

Pageaux, B., Marcora, S. M., Rozand, V., \& Lepers, R. (2015). Mental fatigue induced by prolonged self-regulation does not exacerbate central fatigue during subsequent whole-body endurance exercise. Frontiers in Human Neuroscience, 9, 67. https://doi.org/10.3389/ fnhum.2015.00067

Pigeon, W. R., Sateia, M. J., \& Ferguson, R. J. (2003). Distinguishing between excessive daytime sleepiness and fatigue: Toward improved detection and treatment. Journal of Psychosomatic Research, 54(1), 61-69. https://doi.org/10.1016/S0022-3999(02)00542-1

Pike, N. (2011). Using false discovery rates for multiple comparisons in ecology and evolution. Methods in Ecology and Evolution, 2(3), 278-282. https://doi.org/10.1111/j.2041-210X.2010.00061.x

Prak, R. F., van der Naalt, J., \& Zijdewind, I. (2019). Self-reported fatigue after mild traumatic brain injury is not associated with performance fatigability during a sustained maximal contraction. Frontiers in Physiology, 9, 1919. https://doi.org/10.3389/fphys.2018.01919

R Core Team. (2018). R: A language and environment for statistical computing. Vienna, Austria: R Foundation for Statistical Computing.

Rattey, J., Martin, P. G., Kay, D., Cannon, J., \& Marino, F. E. (2006). Contralateral muscle fatigue in human quadriceps muscle: Evidence for a centrally mediated fatigue response and cross-over effect. European Journal of Applied Physiology, 452, 199-207. https://doi. org/10.1007/s00424-005-0027-4

Renfree, A., West, J., Corbett, M., Rhoden, C., \& Gibson, S. C. A. (2012). Complex interplay between determinants of pacing and performance during 20-km cycle time trials. International Journal of Sports Physiology and Performance, 7(2), 121-129. https://doi. org/10.1123/ijspp.7.2.121

Ross, E. Z., Middleton, N., Shave, R., George, K., \& Nowicky, A. (2007). Corticomotor excitability contributes to neuromuscular fatigue following marathon running in man. Experimental Physiology, 92(2), 417-426. https://doi.org/10.1113/expphysiol.2006.035972

Rossi, S., Hallett, M., Rossini, P. M., \& Pascual-Leone, A. (2011). Screening questionnaire before TMS: An update. Clinical Neurophysiology, 122(8), 1686. https://doi.org/10.1016/j.clinph.2010.12.037

Šambaher, N., Aboodarda, S. J., \& Behm, D. G. (2016). Bilateral knee extensor fatigue modulates force and responsiveness of the corticospinal pathway in the non-fatigued, dominant elbow flexors. Frontiers in Human Neuroscience, 10, 18. https://doi.org/10.3389/fnhum.2016.00018

Sidhu, S. K., Bentley, D. J., \& Carroll, T. J. (2009). Locomotor exercise induces long-lasting impairments in the capacity of the human motor cortex to voluntarily activate knee extensor muscles. Journal of Applied Physiology, 106(2), 556-565. https://doi.org/10.1152/ japplphysiol.90911.2008

Sidhu, S. K., Weavil, J. C., Venturelli, M., Garten, R. S., Rossman, M. J., Richardson, R. S., ... Amann, M. (2014). Spinal $\mu$-opioid receptor-sensitive lower limb muscle afferents determine corticospinal responsiveness and promote central fatigue in upper limb muscle. Journal of Physiology, 592(22), 5011-5024. https://doi. org/10.1113/jphysiol.2014.275438

Smith, S. A., Querry, R. G., Fadel, P. J., Gallagher, K. M., Stromstad, M., Ide, K., ... Secher, N. H. (2003). Partial blockade of skeletal muscle somatosensory afferents attenuates baroreflex resetting during exercise in humans. Journal of Physiology, 551, 1013-1021. https://doi.org/10.1113/jphysiol.2003.044925

Souron, R., Besson, T., Mcneil, C. J., Lapole, T., \& Millet, G. Y. (2018). An acute exposure to muscle vibration decreases knee extensors force production and modulates associated central nervous system excitability. Applied Physiology, Nutrition and Metabolism, 43, 427-436. https://doi.org/10.3389/fnhum.2017.00519

St Clair Gibson, A., Baden, D. A., Lambert, M. I., Lambert, E. V., Harley, Y. X. R., Hampson, D., ... Noakes, T. D. (2003). The conscious perception of the sensation of fatigue. Sports Medicine, 33(3), 167-176. https://doi.org/10.2165/00007256-200333030-00001

Staiano, W., Bosio, A. B., de Morree, H. M., Rampinini, E., \& Marcora, S. M. (2018). The cardinal exercise stopper: Muscle fatigue, muscle pain or perception of effort? Progress in Brain Research, 240, 175-200. https://doi.org/10.1016/bs.pbr.2018.09.012

Stephan, K. E., Manjaly, Z. M., Mathys, C. D., Weber, L. A. E., Paliwal, S., Gard, T., ... Petzschner, F. H. (2016). Allostatic self-efficacy: A metacognitive theory of dyshomeostasis-induced fatigue and depression. Frontiers in Human Neuroscience, 10, 550. https://doi. org/10.3389/fnhum.2016.00550

Temesi, J., Gruet, M., Rupp, T., Verges, S., \& Millet, G. Y. (2014). Resting and active motor thresholds versus stimulus-response curves to determine transcranial magnetic stimulation intensity in quadriceps femoris. Journal of Neuroengineering and Rehabilitation, 11(1), 40. https://doi.org/10.1186/1743-0003-11-40

The jamovi project. (2019). jamovi (1.0). Retrieved from https://www. jamovi.org

Todd, G., Taylor, J. L., \& Gandevia, S. C. (2016). Measurement of voluntary activation based on transcranial magnetic stimulation over the motor cortex. Journal of Applied Physiology, 121(3), 678-686. https://doi.org/10.1152/japplphysiol.00293.2016

Triscott, S., Gordon, J., Kuppuswamy, A., King, N., Davey, N., \& Ellaway, P. (2008). Differential effects of endurance and resistance training on central fatigue fatigue. Journal of Sports Sciences, 26(9), 941-951. https://doi.org/10.1080/02640410701885439

Volz, L. J., Eickhoff, S. B., Pool, E.-M., Fink, G. R., \& Grefkes, C. (2015). Differential modulation of motor network connectivity during movements of the upper and lower limbs. NeuroImage, 119, 44-53. https://doi.org/10.1016/j.neuroimage.2015.05.101

Zénon, A., Sidibé, M., \& Olivier, E. (2015). Disrupting the supplementary motor area makes physical effort appear less effortful. Journal of Neuroscience, 35(23), 8737-8744. https://doi.org/10.1523/ JNEUROSCI.3789-14.2015

How to cite this article: Greenhouse-Tucknott A, Wrightson JG, Raynsford M, Harrison NA, Dekerle J. Interactions between perceptions of fatigue, effort, and affect decrease knee extensor endurance performance following upper body motor activity, independent changes in the neuromuscular function. Psychophysiology. 2020;00:e13602. https://doi. org/10.1111/psyp.13602 